NBER WORKING PAPER SERIES

\title{
WHERE HAVE ALL THE YOUNG MEN GONE? USING GENDER RATIOS TO MEASURE FETAL DEATH RATES
}

\author{
Nicholas J. Sanders \\ Charles F. Stoecker \\ Working Paper 17434 \\ http://www.nber.org/papers/w17434 \\ NATIONAL BUREAU OF ECONOMIC RESEARCH \\ 1050 Massachusetts Avenue \\ Cambridge, MA 02138 \\ September 2011
}

We thank Douglas Almond, Alan Barreca, Scott Carrell, Caroline Hoxby, Hilary Hoynes, Douglas L. Miller, Hendrik Wolff, and participants in the University of California, Davis Brownbag Series, the Stanford Environmental and Energy Policy Center Brownbag Series, the Atmospheric Aerosols \& Health Seminar Series, the NBER Children's Program Meeting, the Western Economic Association International 86th Annual Conference, and the NBER Environmental and Energy Economics Summer Institute. The views expressed herein are those of the authors and do not necessarily reflect the views of the National Bureau of Economic Research.

NBER working papers are circulated for discussion and comment purposes. They have not been peerreviewed or been subject to the review by the NBER Board of Directors that accompanies official NBER publications.

(C) 2011 by Nicholas J. Sanders and Charles F. Stoecker. All rights reserved. Short sections of text, not to exceed two paragraphs, may be quoted without explicit permission provided that full credit, including $\odot$ notice, is given to the source. 
Where Have All the Young Men Gone? Using Gender Ratios to Measure Fetal Death Rates

Nicholas J. Sanders and Charles F. Stoecker

NBER Working Paper No. 17434

September 2011

JEL No. I12,Q51,Q53

\begin{abstract}
Fetal health is an important consideration in the formation of health-based policy. However, a complete census of true fetal deaths is impossible to obtain. We present the gender ratio of live births as an under-exploited metric of fetal health and apply it to examine the effects of air quality on fetal health. Males are more vulnerable to side effects of maternal stress in utero, and thus are more likely to suffer fetal death due to pollution exposure. We demonstrate this metric in the context of the Clean Air Act Amendments of 1970 (CAAA) which provide a source of exogenous variation in county-level ambient total suspended particulate matter (TSPs). We find that a standard deviation increase in annual average TSPs (approximately $35 \mu \mathrm{g} / \mathrm{m}^{3}$ ) decreases the percentage of live births that are male by 3.1 percentage points. We then explore the use of observed differences in neonatal and one-year mortality rates across genders in response to pollution exposure as a metric to estimate total fetal losses in utero. These calculations suggest the pollution reductions from the CAAA prevented approximately 21,000-134,000 fetal deaths in 1972.
\end{abstract}

Nicholas J. Sanders

Stanford University

366 Galvez Street, Room 228

Stanford, CA 94305-6015

sandersn@stanford.edu

Charles F. Stoecker

Department of Economics

One Shields Ave

Davis, CA 95616

cfstoecker@ucdavis.edu 


\section{Introduction}

Improvements in air quality have led to observed improvements in health outcomes such as birth weight and infant mortality, but, as noted by (Currie, 2011), these measures are downward biased estimates of the true effects since they cannot account for selection in utero. As policy choices based only on traditional infant health outcomes may not be made with full information, greater information about fetal death effects would clearly be useful in effective policy construction. Unfortunately, fetal death data are rarely available and selectively measured, making it difficult to estimate the impacts of policy interventions. Examining policy effects on total birth rates cannot be used as an effective measure of fetal deaths, as fertility choices such as frequency of intercourse or other behavioral decisions could also change in response to the policy intervention. We instead present the gender ratio of live births as a metric to assess changes in fetal and maternal health.

We first provide an overview of research suggesting males are more sensitive than females to negative health shocks in utero, and then discuss the evolutionary biology behind this difference. We next consider births in the United States between 1969 and 1988 and show that, over time, there are persistent differences in the share of live births that are male across subgroups in ways which evidence would suggest align with fetal health, an idea shown in more recent data by Almond and Edlund (2007). In light of this evidence, we explore the use of the gender ratio of live births to estimate fetal death rates, using the impact of prenatal exposure to ambient total suspended particulate matter (TSPs) on fetal death as an example. We next consider using the observable gender differences in pollution-driven neonatal mortality rates as an estimate of relative gender sensitivity, and convert gender ratio changes into an estimate of total fetal deaths caused by ambient TSPs.

The gender ratio for live births, unlike total fertility, is largely orthogonal to other choice-based fertility factors correlated with changes in pollution or other health stressors, and thus provides a less biased measure of fetal deaths. This does not make it a panacea for the problem of fetal 
death estimation. Relationships between the gender of live births and socioeconomic status make cross sectional analysis of pollution and gender ratios difficult (Almond and Edlund, 2007; Currie, 2011). We therefore demonstrate this metric in the context of a panel data, instrumental variables strategy, using the Clean Air Act Amendments of 1970 (CAAA) as an exogenous driver of ambient TSP levels, an identification strategy was first used in Chay and Greenstone (2003a) and Chay, Greenstone, and Dobkin (2003) to help identify the impact of TSPs on adult and infant health. We focus on the CAAA since it provides a dramatic decrease in pollutant levels, in a modern setting, and is cleanly identified by an exogenous policy shock. We use estimated CAAA regulation as an instrument for changes in ambient pollution levels between 1970-1972, and then use a firstdifference model to estimate the effect of pollution on the gender ratio.

We find a statistically and economically significant association between ambient TSP levels and the fraction of live births that are male: a one unit increase in annual ambient TSP levels is associated with approximately a 0.088 percentage point change in the probability of a live birth being male, and a standard deviation increase in the annual average TSPs (approximately 35 micrograms per cubic meter) is associated with a 3.1 percentage point change. ${ }^{1}$ These effects are larger when considering particularly vulnerable subgroups, such as less educated mothers, single mothers, and black children.

We convert this gender ratio change into a potential measure of fetal deaths prevented by the TSP reductions caused by the CAAA. We discuss a number of possible metrics, and estimate a range of 21,000 to 134,000 avoided fetal deaths, or 2 to 13 percent of the birth population in those counties. As a point of comparison, using a method similar to Chay and Greenstone (2003a) (hereafter CG), we find the reductions between 1970 and 1972 caused by the CAAA prevented approximately 2,100 infant deaths. ${ }^{2}$ This suggests a higher sensitivity to TSPs in utero than after birth, and there are substantial health improvements due to reduced air pollution not currently

\footnotetext{
${ }^{1}$ Baseline values refer to the value in attainment counties in our sample in 1970.

${ }^{2}$ Note our estimate varies from CG due to differences in available data and a consequently slightly different choice of period of interest.
} 
quantified in the economics literature.

We also contribute to the literature on gender differences in response to external shocks. Prior research has focused largely on rare, one-time events(Lyster, 1974; Fukuda et al., 1998; Almond, Edlund, and Palme, 2007; Peterka, Peterková, and Likovský, 2007; Almond et al., 2007; Catalano, 2003; Kemkes, 2006; Catalano, Bruckner, and Ahern, 2010). Other work has examined more frequently experienced shocks including temperature (Lerchl, 1999; Catalano, Bruckner, and Smith, 2008; Helle, Helama, and Jokela, 2008), alcohol consumption (Nilsson, 2008), and job loss (Catalano et al., 2010). To our knowledge, this is the first paper to use a quasi-experimental, panel data design to consider the differential gender impacts caused by a common air pollutant. ${ }^{3}$

The remainder of this paper is organized as follows. Section 2 presents evidence of gender differences in susceptibility to external stress, and discusses the potential effects of pollution on fetal health. Section 3 discusses differences in baseline gender ratios across subgroups. Section 4 provides some background on the CAAA. Section 5 outlines our identification strategy. Section 6 describes the data used in the analysis. Section 7 describes our main results. Section 8 places our findings in context with prior work. Section 9 concludes.

\section{Environmental stressors, fetal susceptibility, and gender effects}

The health consequences of early-life exposures to environmental externalities have received a good deal of attention in applied research as of late. Lead has been linked to lowered IQ and increased aggression (Reyes, 2007; Nilsson, 2009) and increased infant mortality (Clay, Troesken, and Haines, 2010). Carbon monoxide has been linked to increased infant mortality (Currie and Neidell, 2005), low birth weight and preterm birth (Ritz and Yu, 1999; Currie, Neidell, and Schmieder, 2009), and increased school absences in young children (Currie et al., 2009). Ozone has been

\footnotetext{
${ }^{3}$ Note that our identification uses the drastic reduction in TSPs seen during the aftermath of the CAAA. Modern particulate levels are far lower in the United States. If effects are nonlinear, we may be estimating an upper bound of the effects seen today. In other currently industrializing countries, particulate levels are currently as high as they were during our period of analysis, if not higher.
} 
linked to higher asthma rates and cardiac difficulties (Neidell, 2004, 2009; Lleras-Muney, 2010; Moretti and Neidell, 2011). Particulate matter has been found to increase infant mortality rates (Chay and Greenstone, 2003b,a; Knittel, Miller, and Sanders, 2011), as well as the incidence of low birth weight (Wang et al., 1997). Studies on less pollutant-specific environmental factors such as proximity to traffic pollution (Currie and Walker, 2011), presence of toxic releases (Currie and Schmieder, 2009), proximity to Superfund cites (Currie, Greenstone, and Moretti, 2011), and presence of a steel mill (Parker, Mendola, and Woodruff, 2008) have found various negative fetal health impacts including low birth weight, premature birth, infant mortality, and congenital anomalies. A more comprehensive review of the fetal environmental literature is available in Currie (2011).

In this paper, we focus on TSPs as our pollutant of interest, the measure of airborne particulate matter used by the EPA during the timeframe of the CAAA. The term TSPs refers to all suspended, airborne liquid or solid particles smaller than 100 micrometers in size. ${ }^{4}$ Exposure to TSPs could harm fetal development by compromising the mother's health or impacting the fetus directly, both of which have been documented in the medical and environmental literature. For example, elevated prenatal radiation exposure has been linked to lower test scores (Almond, Edlund, and Palme, 2009), , and particulate exposure linked to lower IQ scores at age 5 (Perera et al., 2009), and high school standardized test performance Sanders (2011). The presence of such fetal damages further supports the hypothesis that TSP exposure can impact the fetus as well as infants. For further discussion of how negative fetal shocks (environmental and otherwise) can have lasting life effects, see Almond and Currie (2011).

Our use of the gender ratio as a measure of fetal deaths is based on the evolutionary theory that women in poor health are more likely to produce female children than male children. This hypothesis, first proposed by Trivers and Willard (1973), can be summarized as follows: carrying

\footnotetext{
${ }^{4}$ As monitoring technology has advanced, regulatory attention has shifted to finer sizes of particulate matter, with much of the attention now on two size classifications: particulate matter smaller than 10 micrometers (PM10) and particulate matter smaller than 2.5 micrometers (PM2.5). Both of these size classifications are contained with the older TSP measure.
} 
a fetus to term is costly and it is beneficial to ensure the ensuing child will produce grandchildren. Since a man can simultaneously father children with multiple women, men in good health could secure several mates, and men in poor health might secure none. For women the relationship between health and mating is less pronounced, as women in poor health can still secure mating opportunities with men in good health. If maternal health is an indicator for potential future infant health conditions, the Trivers-Willard hypothesis predicts that mothers are more likely to favor daughters when in poor health themselves, as this will maximize the mating opportunities for their children, and thus also maximize their chances of having grandchildren.

In our context, exposure to pollutants may compromise the health of the mother, sending a signal to the mother's reproductive system that she is in poor health and that her offspring will also be born into poor health. The Trivers-Willard mechanism suggests this could lead to a lower probability of a live male birth. Such favoring could occur via male fetal loss, or shortly after conception via preventing implantation of male embryos. Work in the medical and economics literature using research designs that can isolate stressors during gestation from those that occurred around the time of implantation suggests differential implantation cannot be the sole mechanism of altering gender ratios. For example, Cagnacci et al. (2004) find weight gain during pregnancy had negative impacts on the probability of bearing a male child, and Almond, Edlund, and Palme (2007) find that fallout from the Chernobyl disaster had significant negative impacts on the percentage of live births that are male for cohorts that were in their second trimester during the disaster. Nilsson (2008) finds lower alcohol prices, and the associated increase in consumption, decreased the percentage of male births among cohorts that had been conceived prior to the price decrease. We examine pollution effects differently by trimester of gestation and find similar effects across all three trimesters, and conclude that differential implantation rates by gender in response to pollution are a small part of the total share. Henceforth, we use the term fetal death to encompass both failed implantations and post-implantation fetal deaths. Unfortunately, the direct mechanism through which TSPs might influence either maternal or fetal health is unknown. For the remainder of the 
analysis we focus on the causal relationship between higher pollution rates and fetal death but do not attempt to identify the direct mechanism through which this effect operates.

\section{Gender and Birth Trends in the United States}

Given the prior that male fetuses are "weaker", we would expect to see a greater number of females for subgroups of the population who are more likely to be exposed to stressors (e.g. pollution, nutrient depravation, smoking, alcohol consumption, etc.) or and/or less likely to have fetal "damage abatement" capital (e.g., prenatal care). In Table 1, we show the mean percentage of live births that are male by subgroup for 1968-1988, the years for which natality data by county and gender are publically available.

As was documented by Almond and Edlund (2007), there are differences in the gender ratio among subgroups, and all differences move in the anticipated direction. A male birth is less likely for mothers with lower education, single mothers, younger and older mothers, black mothers, mothers that delayed prenatal care, and mothers that gave birth in quarters 1 and 4 (see Buckles and Hungerman (2008)). In Section 7, we explore differences in the impact of pollution across such subgroups (when sufficient data are available) and find in all cases that the effects are largest for those with the greatest susceptibility to fetal loss (as indicated by the baseline gender ratio).

Sex ratios of live births do not only vary across groups, but across time as well. The live birth gender ratio in the United States as of 2006 was approximately 1.05 males per female. This translates to the probability of any one live birth being male of approximately 51.21 percent, a value comparable to the 51.29 percent estimated within our time period. The sex ratio at birth in the United States has slowly fluctuated over the years, with a largely constant downward trend beginning in the 1970s. Currently, no known explanation exists for the gradual decrease in the share of live male births, though a number of theories have been proposed. Mathews and Hamilton (2005) specifically notes changes in the age of the father, lower maternal weight, stress, and environmental toxins as potential factors previously studied in the literature. 
Most relevant to our period of interest is the shift in trend in 1970, which was accompanied by a brief downward swing in the share of overall live births that are male. Between 1970 and 1972, there was a nationwide drop in the share of male births, with a reversal of almost equal size occurring in 1973 and 1974 (see Mathews and Hamilton (2005)). As with the general trend in gender ratios, no current theory can explain this particular dip. What is clear is that such general movements can make OLS identification problematic, which drives our use of the CAAA as an instrument for pollution levels and a potential solution to the estimation complications driven by general gender and pollution trends. The fundamental assumption is that the nonattainment counties serve as good counterfactuals for attainment counties. We discuss this further below, and investigate this issue in detail in the appendix.

Table 2 shows that, despite changes in the average gender ratio at live birth over time, there remain differences between the more susceptible vs. less susceptible groups discussed in Table 1. Columns 1 through 5 show differences over time by: first prenatal care use (7-9 months vs. 1-3 months), marital status (married vs. single), mother age (over 35 vs. 19-35), child race (white vs. black), and maternal education (above high school vs. high school and below). In each case, the percentage of live births that are male in the disadvantaged group is subtracted from the same percentage from the advantaged group. Over all periods between 1969 and 1988, there remain differences between said groups. In nearly all group and year cells, the difference is in the direction predicted, namely the advantaged group has more male live births as a percentage of total births than the disadvantaged group.

\section{The Clean Air Act Amendments of 1970 and ambient pollution}

On December 31, 1970 President Richard Nixon signed the first round of Clean Air Act Amendments which required states to prepare and submit plans for regulating ambient pollution by January, 1972. As part of its attempt to reduce ambient pollution, the federal government classified regions as being in "attainment" or "nonattainment" based on regulatory caps on various pollu- 
tants. Regions found to be in nonattainment were subject to more stringent regulation as a result — states were required to establish plant level controls, set emissions caps, and install abatement technologies (for more information on the CAAA and plant response, see Greenstone (2002)). Following CG, we assign attainment status at the county level, assuming that states placed their regulatory attention on individual counties within a regulatory region when deciding how to best lower ambient air measures.

In a given year, areas were deemed to be in nonattainment for TSPs if they violated either of two conditions: (1) the annual geometric mean was greater than $75 \mu \mathrm{g} / \mathrm{m}^{3}$, or (2) the second highest reading for the year was greater than $260 \mu \mathrm{g} / \mathrm{m}^{3}$. We use this nonattainment status as an instrument for pollution changes within counties, where counties that received the "treatment" of being potentially in nonattainment are anticipated to see greater decreases in pollution. Data on actual attainment status in the early 1970s are unavailable. To construct our instrument we must estimate which regions were most likely to be classified as in attainment or not based on the available pollution data. We use TSP monitor data from 1970 to assign likely attainment status at the county level for 1972 (following CG), and when we discuss counties as being in attainment or nonattainment in 1972, we are referring to a status calculated using data from 1970 levels. This assumes that, in order to write their implementation plan in time for the January 1972 deadline, states would have needed to use pollution information from 1970, as 1971 data were not yet available.

Figure 1 shows the distribution of 1970 pollution levels for counties in our sample using a bandwidth of $10 \mu \mathrm{g} / \mathrm{m}^{3}$. The regulatory cutoff point of $75 \mu \mathrm{g} / \mathrm{m}^{3}$ is indicated with a vertical dashed line. We examine the change in pollution levels between 1970 and 1972 to span a period prior to and just following the enactment of the CAAA. 


\section{Estimation strategy}

We utilize a quasi-experimental strategy that exploits variation in pollution levels across counties and over time. For some county $c$ in year $t$, the relationship between a county level outcome of interest $y$ and ambient pollution can be expressed as

$$
y_{c, t}=\alpha+\beta T S P_{c, t}+\delta X_{c, t}+\lambda_{c}+\gamma_{s, t}+\epsilon_{c, t}
$$

where $\beta$ is the coefficient of interest (the marginal impact of TSPs), $X_{c, t}$ is a vector of aggregated individual demographic covariates and county-level economic covariates, $\lambda_{c}$ is a time-invariant county level fixed effect, $\gamma_{s, t}$ is a state-by-year fixed effect, and $\epsilon_{c, t}$ is the error term. An analog to the fixed-effects model is the "first-difference" model, where changes in $y$ are expressed as functions of changes in $T S P$ and other covariates. Let $\Delta y_{c}=y_{c, 1972}-y_{c, 1970}$, with similar notation for $T S P, X$, and $\epsilon$. Then,

$$
\Delta y_{c}=\alpha+\beta \Delta T S P_{c}+\delta \Delta X_{c}+\gamma_{s}+\Delta \epsilon_{c}
$$

Time-invariant factors such as $\lambda_{c}$ have been eliminated with the difference, and the state-by-year fixed effects become state fixed effects in our specification that has only two years. The remaining error may still have period-specific, county-level unobserved factors. This will contribute to bias in the ordinary least squares (OLS) estimates if such unobserved factors are correlated with the estimate of interest even after controlling for covariates, i.e.,

$$
E\left[\Delta T S P_{c}, \Delta \epsilon_{c} \mid \Delta X_{c}\right] \neq 0
$$

OLS results can also suffer from measurement error, which, if classical, will bias results toward zero. Pollution is assigned at the county level, an inherently noisy measure of true individual 
exposure. In addition, we are considering prenatal effects, and the exact exposure timeframe is unknown. ${ }^{5}$ Any fixed-effects type model will accentuate existing measurement error, as such models remove some true variation while doing nothing to eliminate random noise, increasing the noiseto-signal ratio.

In order to obtain unbiased estimates, we use estimated 1970 county-level attainment status as an instrument for changes in pollution, similar to Chay and Greenstone (2003a). We let $\mathbf{1}(\bullet)$ be an indicator function equal to one if the county appeared to surpass the nonattainment threshold, namely:

$$
\mathbf{1}(\bullet)=\left\{\begin{array}{rr}
1 & \text { if }\left(\text { geometric mean }_{c, 70}>75 \text { or } 2^{\text {nd }} \text { highest }_{c, 70}>260\right) \\
0 & \text { otherwise }
\end{array}\right.
$$

and then pursue the following instrumental variables approach:

$$
\begin{aligned}
\Delta y_{c} & =\alpha+\beta \Delta \widehat{T S} P_{c}+v \mathbf{1}(\bullet) T S P_{1970}+\rho(1-\mathbf{1}(\bullet)) T S P_{1970}+\delta \Delta X_{c}+\gamma_{s}+\Delta \epsilon_{c} \\
\Delta T S P_{c} & =\kappa+\mathbf{1}(\bullet)+\pi \mathbf{1}(\bullet) T S P_{1970}+\tau(1-\mathbf{1}(\bullet))+\phi \Delta X_{c}+\gamma_{s}+\eta_{c}
\end{aligned}
$$

where $\eta$ is the first stage error term and $T S P_{1970}$ is normalized to zero at the regulatory threshold. We assume that attainment status is uncorrelated with the errors in the second stage. This correlation could be present if, for example, pollution decreases are driven by mean reversion rather than attainment status. To allow for potential secular trends in pollution reduction across pollution levels before the CAAA we add a linear control for 1970 TSP level. This is particularly important given our use of the regression discontinuity design in the first stage — the inclusion of the variable that determines treatment, or the "running variable" verifies the effect is driven by the discontinuity of treatment. Our main specification also allows the slope to vary on either side of

\footnotetext{
${ }^{5}$ Even for live births, reported gestation length information is imprecise. We test to see if exposure calculated using daily pollution data over an estimated gestation yields different results in Section 7 and find results consistent with our main specification.
} 
the cutoff to allow the relationship between initial pollution level and subsequent change to be different for counties with initially high or low pollution levels. In the appendix we explore variations on this specification, including higher order controls and sample selections centered more tightly around the threshold.

Panel A of Figure 2 illustrates the raw pollution levels between counties estimated to be in attainment and those that were not. There is a general trend of declining pollution levels over the period of interest. Between 1970 and 1972 air pollution in attainment counties increased slightly, while the declines in nonattainment counties were dramatic. This change is more clearly illustrated in Panel B, which shows pollution levels by attainment status relative to their 1960 levels. Here, we can see that changes in both county groups move together before and after the 1970-1972 period, but differ drastically within that timeframe.

To illustrate this further, we next regress 1970-1972 changes in the arithmetic mean on all covariates of interest and state fixed effects and then plot the residuals, weighted by number of births. We also include predicted values from a local linear regression (with a bandwidth of 30 $\mu \mathrm{g} / \mathrm{m}^{3}$ ) of the residuals on the 1970 geometric mean, including an indicator for the attainment status and allowing the slope to vary on either side of the cutoff. Figure 3 shows this relationship. Clearly, there are two different patterns of change on either side of the cutoff, where changes are more drastic for nonattainment counties. We note that nonattainment counties just to the right of the cutoff behave somewhat differently than those further out in the pollution distribution. This could be due to the imprecision of our assignment of attainment status (discussed in Section 4), or it could indicate that higher pollution counties are different from those closer to the cutoff in their pollution changes. This is important given the use of a regression discontinuity in our first stage, and results should be interpreted with this caveat in mind. We explore this to a greater degree in the appendix, where we explore the robustness of our results to different specifications and bandwidths.

Panel A of Table 4 shows the numerical relationship between assigned attainment status and 
changes in pollution. All standard errors are clustered at the state level. In column 1, we regress the 1970-1972 pollution change on only state fixed effects and an indicator for estimated 1970 attainment status. Column 2 adds natality controls for our observed births, which helps control for potential changes in maternal composition. Column 3 adds economic controls. Column 4 adds a control for the 1970 geometric mean, which serves as the running variable in the regression discontinuity that provides the instrument for the IV regressions. Column 5, our preferred specification, allows the running variable to have different slopes on either side of the regulatory cutoff. Here, counties classified as being in nonattainment saw pollution drops that were around $12 \mu \mathrm{g} / \mathrm{m}^{3}$ greater on average than attainment counties. In all instrumental variables regressions that follow, we show the standard F-statistics for first stage regressions as a demonstration of the strength of the first stage.

\section{Data}

We combine data from birth records, death records, ambient TSP measurements, and local economic indicators to create a balanced panel of counties with data from 1970 and $1972 .{ }^{6}$ Birth data come from the National Center for Health Statistics Vital Statistics Micro-data. Data begin in 1968, and from 1968-1972 represent a 50\% sample of all birth certificates in the United States (weighted up to represent the full population of births). We use county and year of birth to match birth cohorts to their relevant ambient pollution levels. In some specifications, we expand on this by using daily pollution data to calculate exposure levels based on day of birth and then again collapse data to the county-by-year level.

We limit the covariates used in our study to those that are least frequently missing in our time period. These include the child's race (white, black, and other), whether the birth was in a hospital, whether a physician was present, birth parity, and mother's age. In some specifications we include

\footnotetext{
${ }^{6}$ We also examined the 1969-1972 and 1971-1972 periods. Results were imprecise, and while we could not reject equality across specifications, results from other periods were noisy enough that we could not reject substantially different values as well.
} 
mother's education, though this reduces the number of observed births (and counties) available for estimation. We conduct estimation at the county-by-year of birth level and weight all regressions by the number of observed births with the relevant gender, race, or maternal characteristics in each cell. Incidental to calculating total loss effects, we expand on the infant mortality analysis in CG and examine post-natal mortality by gender. Infant death data, used to examine infant mortality rates, are from the full census of deaths from the National Center for Health Statistics National Vital Statistics System Multiple Cause of Death Files. Demographic variables include race, gender, and age at death. ${ }^{7}$ We construct the neonatal infant mortality rate for year $Y$ by dividing the number of infants born in year $Y$ that died within 28 days by the number of live births in year $Y$ by gender and race. The one-year mortality rate is constructed similarly. After 1982, limited micro-level fetal death data by gender are available in the Vital Statistics Fetal Death Detail Record. In Section 8 , we discuss these data as potential measure of the fetal sensitivity differences across genders. ${ }^{8}$ Pollution data are from the EPA Air Quality Database. We use the reported 24-hour average TSP level and collapse this day-by-station measurement to the year-by-county level using the number of observations as weights. ${ }^{9}$ In order to closely approximate the regulations in the CAAA we estimate each county's attainment status using the geometric mean and second-highest daily measure from the highest reading monitor in the county of pollution data from 1970, a strategy identical to CG (see Section 5). Since many monitors take readings only once per year during the winter, we limit our analysis to monitors with at least 26 readings per year - the number of readings per year required to obtain a balanced distribution of samples across all 12 months. Results using all available monitors were noisier but quantitatively similar and are available upon request.

In order to control for economic confounders potentially correlated with both air quality and fe-

\footnotetext{
${ }^{7}$ We exclude deaths due to external causes (e.g., fractures, injuries, or adverse effects of medical agents) from our analysis. Such deaths are not causally linked with pollution levels (see Table 8 of CG).

${ }^{8}$ While nationally available fetal death data exist prior to 1982, they are aggregated to the race/county level and do not allow for gender comparisons.

${ }^{9}$ We have also explored using the geometric mean as the health-relevant pollution shock. Results are qualitatively similar and available on request.
} 
tal death rates, we use county-level data from the Regional Economic Information System (REIS), provided by the Bureau of Economic Analysis. These data contain annual measures of per capita income, per capita net earnings, and several measures of total government transfer payments which we convert to per capita: total transfers, total medical transfers, public assistance medical payments, income maintenance, family assistance payments, food stamps payments, and unemployment insurance. We also control for county level employment (total employment divided by total population), employment in manufacturing (as the CAAA likely had differential impacts based on the size of the manufacturing sector), and total population. All dollar values control for inflation and are adjusted to 2009 dollars.

After combining all data sets, we have 281 counties in our primary analysis, which represent almost $50 \%$ of all live births over 1970 and 1972. Summary statistics by attainment status across our period of interest are shown in Table 3. In general, inputs related to birth outcomes are similar for attainment counties and nonattainment counties over the two years of interest. The last column reports the p-value from a regression of the variable of interest on the difference-in-difference estimate between attainment and nonattainment counties across 1970-1972. Nonattainment status was not randomly assigned, so we expect that high pollution counties will be different from low pollution counties, and they are on several measures. Nonattainment counties are generally more populous, have higher infant mortality rates, and more a higher share of infants are of low birth weight. However, differences in changes in covariates across time are rarely significant. Among the twenty health capital controls, the only statistically significantly different change between attainment and nonattainment counties occurred in income maintenance and family assistance payments. Given prior findings on government assistance programs and live birth gender ratios (Almond, Hoynes, and Schanzenbach, 2011), it is clearly important we control for such factors in our regressions. 


\section{Results}

Here we focus on the discussion of pollution, gender ratios at birth, and fetal death. We note that our identification design is contingent upon the validity of the CAAA as an instrument, which in turn requires assumptions about the regression discontinuity design and excludability of the treatment from the second stage. While we believe our demonstration of the validity of the CAAA is original, since this instrument has been previously introduced to the economics literature and is not the main contribution of this paper, we reserve the detailed exploration of these for the appendix.

As discussed in Section 2, prior research suggests that the male fetus is more sensitive to external stressors, and thus more likely to suffer fetal death in the presence of negative health shocks. If pollution exposure has a positive impact on fetal death rates, and males are more likely to suffer fetal death, than one expected outcome of higher pollution levels is a decrease in the share of live births that are male. By considering changes in the gender ratio as they correlate to changes in ambient pollution, we can observe an indirect measure of the number of male births that did not occur but would have in the absence of air pollution exposure. The gender ratio at birth presents an alternative measure of fetal health that has the advantage of being orthogonal to these parental conception decisions. ${ }^{10}$ This is not a precise measure of the true fetal death rate, as it does not consider any effects on females (and in fact treats the effect on females as zero). In Section 8, we expand on these findings and discuss methods to estimate the total fetal death effect.

A raw data comparison of the change in the fraction of live births that are male by attainment status is illustrated in Figure 4. The change in the fraction of births that are male between 1970-1972 is more positive for nonattainment counties than attainment counties — changes for attainment counties are mildly negative, as discussed in Section 3. This is consistent with reductions

\footnotetext{
${ }^{10}$ Individuals may choose to engage in behavior that they believe impacts the gender of the child. We do not attempt to address whether such behaviors are effective or not. Unless individuals modify this behavior in response to the CAAA attainment status of their home county, such activities should have no impact on the findings for this particular application.
} 
in pollution stemming from the CAAA leading to increases in fetal health, though the graph does not control for any covariates. Panel B of Table 4 presents the reduced form numerically, allowing for the inclusion of controls to better identify the causal effect. Our preferred specification in column 5 indicates that the CAAA increased the fraction of births that are male by 1.02 percentage points. This result is significant at the $1 \%$ confidence level. We note here that column 3 of Panel B serves as a difference-in-difference estimate of the impact of the CAAA on the gender ratio, a result of using the first-difference model with the indicator for nonattainment.

Table 5 shows the estimated relationship between the share of births that are male and ambient TSPs. The outcome variable is the probability of a live birth being male. Coefficients should be interpreted as percentage point changes. We weight each cell by the number of observed live births and standard errors are clustered on state. ${ }^{11}$ Negative marginal impacts indicate higher pollution levels are correlated with a lower fraction of males among live births, which in turn suggests an increase in the fetal mortality rate among males (or a decrease in the number of conceived males, an alternative which we address in Section 8). All regressions include natality controls for observed births, economic controls, and state fixed effects (following DiNardo and Lee (2011), Table B-1 in the appendix shows how our results vary with the inclusion of different covariate sets - they are stable across specifications though more precisely estimated with the inclusion of the full covariate set). Column 1 presents OLS results, while columns 2, 3, and 4 use our instrumental variables approach. Column 2 includes all controls in the OLS estimation. Column 3 adds a linear control for the running variable to allow for trends in the first stage. Column 4, our preferred specification, allows for different slopes in the running variable on either side of the regulatory cutoff.

OLS results are effectively zero and statistically insignificant. IV results are consistently negative and statistically significant at either the $5 \%$ or $1 \%$ level. Our preferred specification suggests a standard deviation increase in the annual average pollution level is associated with a 3.1 percentage

\footnotetext{
${ }^{11}$ Results with standard errors clustered on county rather than state are negligibly different and are available on request.
} 
point decrease in the probability of a live birth being male. Using the 1970 attainment county share of male births (51.37) as a baseline, this is a change of approximately $6 \%$.

CG found similar results in their analysis of the CAAA and infant mortality, where OLS effects were statistically indistinguishable from zero, while IV effects were large and significant. There are a number of reasons our IV results might differ from the OLS estimates. Measurement error may bias OLS toward zero, or the local average treatment effect estimated by the IV specifications may be much larger than the average treatment effect. Omitted variables bias could be influencing the OLS results if there is an omitted factor that is positively correlated with changes in both pollution levels and the fraction of live births that are male. For example, counties could be experiencing an economic downturn, which would cause declining pollution levels as well as economic hardship. The declining pollution level in the county would positively impact fetal health, but the economic hardship would negatively impact fetal health, and the OLS estimate of the relationship between pollution and fetal health would be an understatement of the true effect. Using attainment status as an instrument for the change in pollution will avoid this bias, provided that attainment status is independent of such confounding trends. We show in the appendix that our attainment status instrument does not appear correlated with background trends that continue into the post-treatment period.

We next consider the effects of pollution on the gender ratio at birth by subgroups, including mother's education, child's race, mother's age, and mother marital status. If pollution exposure impacts gender ratios though the fetal death mechanism, we expect to see larger impacts on subgroups that are more sensitive, either through lower availability of fetal damage abatement capital such as prenatal care and avoidance behavior, or because of lower baseline fitness and nonlinearities in health effects. Columns 1 and 2 of Table 6 show results for mothers with high school education or lower and greater than a high school education, respectively. There are a lower number of counties due to the lack of reliable mother's education data in the earlier natality data files. Results confirm our prior expectation - mothers with lower education levels (comprising approximately $\frac{3}{4}$ of 
our sample), a factor highly correlated with availability of fetal damage abatement capital, see a substantially larger impact on their gender ratios when exposed to higher pollution levels, and the result remains statistically significant at 5\%. Higher education mothers show no statistically significant effects. Differences in effect also appear when examining effects by race. Column 3 shows the effect for whites which, while still large and significant, is approximately $\frac{1}{5}$ the estimated effect for blacks. The National Center for Health Statistics reported that for live births in 1970, an estimated $72 \%$ of white mothers received prenatal care during the first trimester, compared to $44.2 \%$ of black mothers. $6.3 \%$ of whites either waited until the third trimester or received no prenatal care at all, compared to $16.6 \%$ of black mothers. ${ }^{12}$ These noted differences in use of prenatal care across races further support our prior expectation — blacks have a lower use of prenatal damage abatement capital, and thus see a larger effect on fetal death. Columns 5, 6, and 7 show results for mothers younger than 20, 20 to 34, and 35 years old and up, respectively. Mothers younger than 20 show a larger effect, though it is not significant at conventional levels. Results remain significant for mothers are 20 to 34, but are again insignificant for mothers 35 and older. Finally, results for single and married mothers are shown in columns 8 and 9, respectively. While the estimates are larger for single mothers, the result is statistically insignificant. Results for married mothers are approximately the same as the full sample result.

We next consider how the effects of pollution might vary by time of year. Buckles and Hungerman (2008) have shown that mother's average socioeconomic status is lower during the winter. Since these seasonal differences may be related to maternal and fetal health, we begin by looking for different effects by quarter of birth. Panel A of Table 7 shows effects by quarter of birth. Column 1 is limited to births that occurred between January and March, Column 2 is limited to births that occurred between April and June, and so forth. Results are largest and most significant in the 2nd and 4th quarters. While the 4th quarter finding supports the Buckles and Hungerman hypothesis, we hesitate to extract too much inference from this given the variation in pollution across

\footnotetext{
${ }^{12}$ Table 5 on page 106 of Health, United States, 2010 (National Center for Health Statistics, 2011).
} 
quarter as well. Figure 5, which shows monthly TSP levels over time, shows that while pollution levels are generally declining, there is also cyclicality of pollution levels within each year. Levels are lowest during the fourth quarter and highest during the second quarter, and more relevant to our first-difference estimation strategy, the change in TSPs between 1970 and 1972 appears largest for these two quarters.

As noted in Section 6, our main specifications assign cohort fetal exposure using year of birth. We next calculate each infant's TSP exposure using daily pollution data. Note that "daily" does not mean each monitor has a reading for every day. Many monitors have pollution measures at most every six days, and our pollution data are a noisy measure of the true pollution level in the county. While an infant born in December may not have experienced the pollution levels measured in January of that year, January's levels may help to remove some of the noise from the measures in the subsequent quarters. Without data on the exact date of conception, we assume each gestation was nine months in length, or would have been in the absence of a fetal death. We label the three months before birth the third trimester, the three months before that the second trimester, and the three months before that the third trimester. We then calculate average pollution exposure over those dates. Columns 1 through 3 of Panel B in Table 7 show the results from these calculations by trimester. The first column compares pollution and gender ratio changes for children whose entire calculated first trimester of gestation was within 1970 to those whose entire calculated first trimester of gestation was within 1972. The second column repeats this process for the second trimester, and the third for the third trimester. The fourth column limits the sample to comparisons of children whose entire gestation was within 1970 and 1972. This smaller sample leads to a noisier estimate of the effect of pollution on the gender ratio, but the point estimates are approximately the same, though larger.

Results by trimester suggest that the largest effect exists in the first trimester, though results are statistically insignificant and the first stage is surprisingly weak. The only individual trimester with statistically significant results in the third, in which effects are slightly smaller than our average 
effect. These findings would suggest there may be varied effects across trimester of exposure, but we cannot identify them using our analysis.

\section{Discussion}

Portions of our estimated effect may be driven by some unobservable factors that remain even after utilizing an IV strategy and controlling for covariates and state fixed effects. One such confounder is macroeconomic changes resulting from the CAAA. For example, Greenstone (2002) shows that the CAAA had substantial economic consequences, particularly for the manufacturing sector. Since male fetuses are also more susceptible to fetal death from stressors other than pollution, this could bias our findings if, for example, the CAAA led to job loss in nonattainment counties, which then led to decreased mother health, either though income loss or additional non-pollution stress (see Walker (2011)). This would suggest that, as a byproduct of the non-pollution effects of the CAAA, the number of male births should decrease due to the increased stress levels. Similarly, if job loss as a result of the CAAA leads to lower levels of maternal nutrition, findings by Almond, Hoynes, and Schanzenbach (2011) indicate that the fraction of male births should decrease. We find the lower pollution caused by the CAAA is associated with an increase in the number of male births - both of these effects should exert pressure in the opposite direction of our main effect and bias our results toward zero, if at all.

Differences in human capital and stresses across socioeconomic status are correlated with lower male birth rates. In a cross-sectional comparison, Almond and Edlund (2007) find significant differences between gender ratios among socioeconomic groups. Specifically, single mothers with less than a high school education are $0.8 \%$ less likely to have males than married mothers with some college education. This could be problematic if the CAAA is associated with a change in the composition of mothers. Specifically, if in response to the CAAA policies, lower education mothers move out of nonattainment counties (or are more likely to avoid pregnancy), we might 
mistake the change in mother composition as evidence of changes in fetal death rates. ${ }^{13}$ Looking at empirical data cannot answer this question, as the composition of mothers might change due to fetal deaths as well - the characteristics of mothers that never give birth are just as unobservable as births that never occur. However, we can place bounds on the potential bias. The reduced form result in Table 4 suggest that the CAAA led to a change in the probability of a male birth of approximately 1 percentage point, which is an increase of approximately $2 \%$ from a 1970 attainment county mean of 51.37. If, prior to the CAAA, every birth in nonattainment counties were to a single mother without a high school degree, and afterward every birth were to a married mother with some college, the implied change would only be able to explain around $50 \%$ of our estimate.

We note that the estimated effects need not necessarily be limited to pregnancies that suffered from fetal death after successful insemination. Our results may include within them not only fetal deaths, but avoided initial pregnancies, though effects on the sex ratio for pollution exposure in the estimated second and third trimesters suggest this is at most a portion of the effect. ${ }^{14}$

\subsection{Estimating total fetal deaths}

Our findings presented thus far have not accounted for any sensitivity of female fetuses to pollution. We now combine our findings, which calculate the difference in losses between males and females in utero, with several estimates of relative in utero sensitivities of males and females to estimate the total fetal losses. We use the relative causal impacts of pollution on neonatal deaths and the relative causal impacts of pollution on deaths within one year to provide a range of plausible estimates of

\footnotetext{
${ }^{13}$ See Dehejia and Lleras-Muney (2004) for a discussion of motherhood composition changes and birth outcomes.

${ }^{14}$ Research in the medical field has proposed that observed changes in the gender ratio in response to maternal stressors are the result of stressful situations favoring the implantation of female over male embryos (Cameron, 2004). Sperm carrying the $\mathrm{Y}$ chromosome that determines the male gender may be weaker than those that carry the $\mathrm{X}$ chromosome, or sperm carrying the Y chromosome may combine less efficiently with the egg, and maternal stress may disrupt zygote formation with "Y sperm" more than zygote formation with "X sperm" (Boklage, 2005). If pollution exposure can change the probability of a successful implantation in ways that vary across genders, or can weaken $\mathrm{Y}$ sperm in such a way as to reduce the relative probability of a male zygote, such changes in the male birth population would be interpreted in our findings as male fetal deaths.
} 
the total in utero mortality effect of pollution levels. ${ }^{15}$ We also discuss the observed total male and female fetal deaths reported in the fetal death data between 1982 and 1989, though we note these are not causally linked to pollution.

Panels A and B of Table 8 present the causal impact of pollution on one year and neonatal mortality (death within 28 days of birth) separately for males (column 1) and females (column 2). Each of these four cells is a coefficient from a first-difference regression using changes from 19701972 and controlling for natality covariates, economic covariates, and state fixed effects. Female and male losses during both the one-year and neonatal periods are all positively signed, as were the results found in CG for the overall population. Consistent with our findings of differential fetal loss rates in utero, male live births have higher mortality than females in response to pollution shocks. Panel A estimates each additional unit of TSP leads to an additional 18 male neonatal deaths per 100,000 live male births and 13 female neonatal deaths per 100,000 live female births, an impact ratio of 1.4 to 1 . Panel B presents similar findings for the one-year mortality rate: the increase in the male mortality rate is approximately 22 per 100,000 live male births, while females see a smaller increase of approximately 14 deaths per 100,000 live female births, a ratio of 1.5 to 1 .

Column 4 of Table 8 shows the estimated total fetal impacts using these relative sensitivity estimates. Using neonatal mortality rates, the estimated reduced form impact in Table 4 translates to a combined impact of 134,000 prevented fetal deaths as a result of the CAAA. Using one-year mortality rates, the total effect is estimated at around 105,000 prevented fetal deaths. ${ }^{16}$ As noted

\footnotetext{
${ }^{15}$ While we attribute our findings to changes in TSPs, other unobserved pollutants that are strongly correlated with TSPs could be contributing to the impact we attribute to TSPs. Unfortunately, data on other pollutants are not available for our timeframe. Regardless of the pollutant, however, the reduced form estimate in Table 4 is identifying the impact of the additional CAAA regulation on fetal deaths, and is informative from the standpoint of policy evaluation.

${ }^{16}$ Estimates are obtained by noting that

$$
\beta_{\mathrm{CAAA}}=\frac{M}{M+F}-\frac{(M-\text { maledeaths })}{(M-\text { maledeaths })+\left(F-\frac{1}{\Omega} \text { maledeaths }\right)}
$$

where $\mathrm{M}$ and $\mathrm{F}$ are the 534,599 male and 506,955 female births in the nonattainment counties in 1972 in our sample and $\Omega$ is the sensitivity of males relative to females, provided above. Note per-unit effects calculated using the estimate from Table 5 differ slightly from the per-unit effects calculated by dividing the reduced form estimate by the first stage change in TSP due to nonlinearities in maledeaths in equation (7).
} 
in Section 6, fetal death microdata are available beginning in 1982. These data on observed fetal deaths can also be used to construct a ratio of male to female fetal deaths, though the deaths are not causally linked to pollution. We prefer our estimates that use the causal impact of pollution on relative neonatal mortality rates as we believe those are the closest to the effects of pollution in utero, and are less likely to be biased by the selectivity of measured fetal deaths. However, for completeness we note that for all data available in the 1980s, a period somewhat close to our period of interest, the number of recorded fetal deaths was 133,706 males and 115,553 females, for a relative ratio of $1.16 .^{17}$

We can also derive a lower bound on the total number of fetal deaths by assuming female fetuses are completely immune to the negative health impacts of air pollution and saw no increased survival in response to the CAAA. This lower bound estimates the CAAA prevented 21,000 total deaths (all male) or $2 \%$ of the total birth population.

Using our preferred relative gender susceptibilities, the above calculations translate to a oneunit drop impact of 180-1,255 fewer fetal deaths per 100,000 live births. ${ }^{18}$ These effects may appear large when compared to the literature on pollution and post-natal infant deaths. A number of factors could explain this difference. It is likely that live births are more robust to stresses than a developing fetus, and abatement actions in the presence of health complications are more easily enacted with infants. For example, if air pollution causes an infant to display respiratory difficulty, the infant may be brought to a hospital, where active medical attention helps to offset the negative effects. No such effects can be easily observed with an injured fetus, and treating a fetus is more difficult that providing medical treatment to an infant.

It is informative to consider our effects in the light of other studies that have found gender differences in the presence of other external stresses. Using the 1970 birth ratio for attainment counties as a baseline, our estimates put the change in the probability of a male birth at approxi-

\footnotetext{
${ }^{17}$ Using this relative fetal sensitivity yields a total estimated effect of 305,000.

${ }^{18}$ Marginal impacts are calculated by dividing the estimated number of avoided deaths by the average TSP reduction caused by the CAAA as shown in Panel A of Table 4. This assumes a linear impact of TSPs.
} 
mately $.17 \%$ per unit of TSPs, with the total effect of the CAAA being a change of approximately 2\%. The 2007 working paper version of Almond, Edlund, and Palme (2009) finds that exposure to the fallout from Chernobyl in Sweden resulted in a decrease in the probability of having a male of $1.6 \%$ in Sweden. Using similar identification, Peterka, Peterková, and Likovský (2004) find the radiation-induced change in the number of male births to be almost $4 \%$ for the Czech Republic. Almond, Hoynes, and Schanzenbach (2011) examine the effect of Food Stamp Program (FSP) rollout at the beginning of the third trimester in utero and find that it increases the fraction of births that are male among whites by $0.09 \%$ and blacks by $0.32 \%$. Our effect is within the range of effects observed for Chernobyl radioactive fallout, but larger than the maternal nutritional effects of the FSP. We are unaware of any conversion of health impacts from subclinical levels of radiation or nutritional deficiencies to the reduction in air pollution levels we examine, but we note that findings for other in utero health shocks are qualitatively similar to those we find for air pollution.

There remains the challenge of quantifying the value of the change in gender ratios at birth. 19 In the case of infant mortality, there are measures of the value of a statistical life that can be used to financially quantify the impacts. Fetal deaths, however, are more complicated. Some may occur without the knowledge of the mother, and one could argue the social costs of such foregone pregnancies are no greater than the loss of births resulting from other medical factors such as sterility. Of the fetal deaths that occur in known pregnancies, the social cost should be less than that of an infant death - fewer resources have been invested, and given that the mother can become pregnant again, the largest costs are a shifting of the pregnancy time frame and the psychological impacts. Of course, changes in fetal deaths are also indications of changes in maternal health, but converting changes in the gender ratio to the value of changes in maternal health is difficult. Given these complications, we cannot monetize our estimated impacts.

\footnotetext{
${ }^{19}$ In the very long run, Angrist (2002) notes that excess females at marriage age lead to worse outcomes for females.
} 


\section{Conclusion}

Measuring the impacts of policy on fetal health presents several challenges. Post-natal measures of fetal health are net of selection, as birth weight averages and mortality rates are only observed among those infants that survive to term. Fetal deaths themselves are rarely observed, recorded only for a selected subset of the population, and microdata are unavailable prior to 1982. Policy changes may have causal impacts on fertility choices as well as impacts on fetal health and separating the two can be difficult, making changes in total live births a potentially biased metric. Our solution to these complications is to use changes in the gender ratio of live births as a potential proxy for fetal deaths, which exploits the medical finding that male fetuses are more susceptible to death from external stresses. Such a measure has the advantage that gender determination is orthogonal to many traditional sources of fertility bias, and could be used to estimate the effects of other policy measures intended to improve maternal health and infant outcomes. We demonstrate several possible methods of converting this metric into a measure of total fetal deaths by combining the change in the gender ratio of live births with observed differential effects of the policy post-birth or providing a lower bound by estimating a zero effect of the treatment on females. The benefit of this method is that it can easily be converted into a measure of total births requiring only that the researcher have information regarding, (1) the gender ratio of live births, and (2) the differential effects of the policy on a measurable post-birth outcome by gender, which can be used to extrapolate the total effect from the observed impact on male fetal losses relative to females.

We demonstrate this metric by using the Clean Air Act Amendments of 1970 as an exogenous shock to ambient total suspended particulate pollution to examine the impacts of prenatal pollution exposure on the gender ratio of live births. In the absence of other confounders associated with the CAAA, a change in the gender ratio in the presence of decreased pollution can be interpreted as avoided male fetal deaths. We then scale our findings using TSP-driven neonatal and one-year infant mortality rates to approximate the impact on total fetal deaths. We find that a one-unit de- 
crease in ambient TSP levels is associated with a 0.088 percentage point increase in the probability of a live birth being male, suggesting reducing pollution reduces male fetal deaths. Given the relative sensitivity of males to females in pollution-induced neonatal mortality, we estimate the total impact of the 1970 Clean Air Act to be in the range of 21,000 to 134,000 total avoided fetal deaths. As conventional estimates of the social cost of pollution include only observable infant health outcomes such as mortality and birth weight, they are lower bounds of the true costs. 


\section{References}

Almond, Douglas and Janet Currie. 2011. "Killing Me Softly: The Fetal Orgins Hypothesis." Journal of Economic Perspectives 25 (3):153-172.

Almond, Douglas and Lena Edlund. 2007. "Trivers-Willard at Birth and One Year: Evidence from US Natality Data 1983-2001." Proceedings of the Royal Society B: Biological Sciences 274 (1624):2491-2496.

Almond, Douglas., Lena Edlund, Hongbin Li, and Junsen Zhang. 2007. "Long-term Effects of the 1959-1961 China Famine: Mainland China and Hong Kong.” NBER Working Paper 13384.

Almond, Douglas, Lena Edlund, and Mårten Palme. 2007. “Chernobyl's Subclinical Legacy: Prenatal Exposure to Radioactive Fallout and School Outcomes in Sweden." NBER Working Paper 13347.

- 2009. "Chernobyl's Subclinical Legacy: Prenatal Exposure to Radioactive Fallout and School Outcomes in Sweden.” Quarterly Journal of Economics 124 (4):1729-1772.

Almond, Douglas, Hilary W. Hoynes, and Diane Whitmore Schanzenbach. 2011. "Inside the War on Poverty: The Impact of Food Stamps on Birth Outcomes." Review of Economics and Statistics 93 (2):387-403.

Angrist, Josh. 2002. "How do Sex Ratios Affect Marriage and Labor Markets? Evidence from America's Second Generation.” Quarterly Journal of Economics 117 (3):997-1038.

Boklage, Charles E. 2005. "The Epigenetic Environment: Secondary Sex Ratio Depends on Differential Survival in Embryogenesis." Human Reproduction 20 (3):583.

Buckles, Kasey and Daniel M. Hungerman. 2008. "Season of Birth and Later Outcomes: Old Questions, New Answers.” NBER Working Paper 14573.

Cagnacci, A., A. Renzi, S. Arangino, C. Alessandrini, and A. Volpe. 2004. "Influences of Maternal Weight on the Secondary Sex Ratio of Human Offspring." Human Reproduction 19 (2):442.

Cameron, Elissa. 2004. "Facultative Adjustment of Mammalian Sex Ratios in Support of the Trivers-Willard Hypothesis: Evidence for a Mechanism." Proceedings of the Royal Society 271 (1549):1723-1728.

Catalano, Ralph, Tim Bruckner, and Jennifer Ahern. 2010. "Male Fetal Loss in the US Following the Terrorist Attacks of September 11, 2001.” BMC Public Health 10 (273).

Catalano, Ralph, Claire E. Magerison Zilko, Katherine B. Saxton, and Tim Bruckner. 2010. "Selection in utero: A Biological Response to Mass Layoffs." American Journal of Human Biology 22 (3):396-400. 
Catalano, Ralph A. 2003. "Sex Ratios in the Two Germanies: A Test of the Economic Stress Hypothesis.” Human Reproduction 18 (9):1972.

Catalano, Ralph A., Tim Bruckner, and Kirk R. Smith. 2008. "Ambient Temperature Predicts Sex Ratios and Male Longevity." Proceedings of the National Academy of Sciences 105 (6):22-44.

Chay, Kenneth Y. and Michael Greenstone. 2003a. "Air Quality, Infant Mortality, and the Clean Air Act of 1970.” NBER Working Paper 10053.

- 2003b. "The Impact of Air Pollution on Infant Mortality: Evidence from Geographic Variation in Pollution Shocks Induced by a Recession." Quarterly Journal of Economics 118 (3):1121-1167.

Chay, Kenneth Y., Michael Greenstone, and Carlos Dobkin. 2003. "The Clean Air Act of 1970 and Adult Mortality." Journal of Risk and Uncertainty 27 (3):279-300.

Clay, Karen, Werner Troesken, and Michael R. Haines. 2010. "Lead, Mortality, and Productivity." NBER Working Paper 16480.

Currie, Janet. 2011. "Inequality at Birth: Some Causes and Consequences." American Economic Review 101 (3):1-22.

Currie, Janet, Michael Greenstone, and Enrico Moretti. 2011. "Superfund Cleanups and Infant Health." American Economic Review 101 (3):435-431.

Currie, Janet, Eric A. Hanushek, E. Megan Kahn, Matthew Neidell, and Steven G. Rivkin. 2009. "Does Pollution Increase School Absences?" The Review of Economics and Statistics 91 (4):682-694.

Currie, Janet and Matthew Neidell. 2005. "Air Pollution and Infant Health: What Can We Learn From California's Recent Experience?” Quarterly Journal of Economics 120 (3):1003-1030.

Currie, Janet, Matthew Neidell, and Johannes F. Schmieder. 2009. "Air Pollution and Infant health: Lessons from New Jersey.” Journal of Health Economics 28 (3):688-703.

Currie, Janet and Johannes F. Schmieder. 2009. "Fetal Exposures to Toxic Releases and Infant Health." The American Economic Review 99 (2):177-183.

Currie, Janet and Reed Walker. 2011. “Traffic Congestion and Infant Health: Evidence from EZPass." American Economic Journal: Applied Economics 3 (1):65-90.

Dehejia, Rajeev and Adriana Lleras-Muney. 2004. “Booms, Busts, and Babies' Health.” Quarterly Journal of Economics 119 (3):1091-1130.

DiNardo, John and David S. Lee. 2011. "Program Evaluation and Research Designs." In Handbooks in Economics - Handbook of Labor Economics, Vol 4A, Handbook of Labor Economics, vol. 4, Part 1, edited by Orley Ashenfelter and David Card. Elsevier, 463 - 536. 
Fukuda, Misao, Kyomi Fukuda, Takashi Shimizu, and Henrick Møeller. 1998. "Decline in Sex Ratio at Birth After Kobe Earthquake." Human reproduction 13 (8):2321-2322.

Greenstone, Michael. 2002. "The Impacts of Environmental Regulations on Industrial Activity: Evidence From the 1970 and 1977 Clean Air Act Amendments and the Census of Manufactures." Journal of Political Economy 110 (6):1175-1219.

Helle, Samuli, Samuli Helama, and Jukka Jokela. 2008. "Temperature-Related Birth Sex Ratio Bias in Historical Sami: Warm Years Bring More Sons.” Biology Letters 4 (1):60.

Kemkes, Ariane. 2006. "Secondary Sex Ratio Bariation During Stressful Times: The Impact of the French Revolutionary Wars on a German Parish (1787-1802)." American Journal of Human Biology 18 (6):806-821.

Knittel, Christopher R., Douglas L. Miller, and Nicholas J. Sanders. 2011. “Caution, Drivers! Children Present: Traffic, Pollution, and Infant Health.” NBER Working Paper 17222.

Lerchl, Alexander. 1999. "Sex Ratios at Birth and Environmental Temperatures." Naturwissenschaften 86 (7):340-342.

Lleras-Muney, Adriana. 2010. "The Needs of the Army: Using Compulsory Relocation in the Military to Estimate the Effect of Air Pollutants on Children's Health." Journal of Human Resources 45 (3):549.

Lyster, W. R. 1974. "Altered Sex Ratio After the London Smog of 1952 and the Brisbane Flood of 1965." Journal of Obstetrics and Gynaecology 81:626-631.

Mathews, TJ and B.E. Hamilton. 2005. "Trend Analysis of the Sex Ratio at Birth in the United States." National vital statistics reports 53 (20):1-17.

Moretti, Enrico and Matthew Neidell. 2011. "Pollution, Health, and Avoidance Behavior: Evidence from the Ports of Los Angeles." Journal of Human Resources 46 (1):154-175.

National Center for Health Statistics. 2011. "Health, United States, 2010: With Special Feature on Death and Dying."

Neidell, Matthew. 2009. "Information, Avoidance Behavior, and Health: The Effect of Ozone on Asthma Hospitalizations." Journal of Human Resources 44 (2):450.

Neidell, Matthew J. 2004. "Air Pollution, Health, and Socio-Economic Status: The Effect of Outdoor Air Quality on Childhood Asthma." Journal of Health Economics 23 (6):1209-1236.

Nilsson, J. Peter. 2008. "Does a Pint a Day Affect Your Child's Pay? Unintended and Permanent Consequences of a Temporary Alcohol Policy Experiment." CEMMAP Working Paper.

. 2009. "The Long-term Effects of Early Childhood Lead Exposure: Evidence from the Phase-out of Leaded Gasoline." Mimeo. 
Parker, Jennifer D., Pauline Mendola, and Tracey J. Woodruff. 2008. "Preterm Birth After the Utah Valley Steel Mill Closure: A Natural Experiment." Epidemiology 19 (6):820.

Perera, Frederica P., Zhigang Li, Robin Whyatt, Lori Hoepner, Shuang Wang, David Camann, and Virginia Rauh. 2009. "Prenatal Airborne Polycyclic Aromatic Hydrocarbon Exposure and Child IQ at Age 5 Years." Pediatrics 124 (2):e195-e202.

Peterka, Miroslav, Reneta Peterková, and Z. Likovský, Z. 2004. "Chernobyl: Prenatal Loss of Four Hundred Male Fetuses in the Czech Republic.” Reproductive Toxicology 18 (1):75-79.

—. 2007. "Chernobyl: Relationship Between the Number of Missing Newborn Boys and the Level of Radiation in the Czech Regions." Environmental Health Perspectives 115 (12):1801.

Reyes, Jessica Wolpaw. 2007. "Environmental Policy as Social Policy? The Impact of Childhood Lead Exposure on Crime." The BE Journal of Economic Analysis \& Policy 7 (1):51.

Ritz, Beate and Fei Yu. 1999. "The Effect of Ambient Carbon Monoxide on Low Birth Weight Among Children Born in Southern California Between 1989 and 1993." Environmental Health Perspectives 107 (1):17.

Sanders, Nicholas J. 2011. "What Doesn't Kill you Makes you Weaker: Prenatal Pollution Exposure and Educational Outcomes.” SIEPR Discussion Paper 10-019.

Trivers, Robert L. and Dan E. Willard. 1973. "Natural Selection of Parental Ability to Bary the Sex Ratio of Offspring." Science 179 (4068):90.

Walker, W. Reed. 2011. "Environmental Regulation and Labor Reallocation: Evidence from the Clean Air Act." American Economic Review 101 (3):442-47.

Wang, Xiaobin, Hui Ding, Louise Ryan, and Xiping Xu. 1997. "Association Between Air Pollution and Low Birth Weight: A Community-Based Study." Environmental Health Perspectives 105 (5):514. 


\section{FIGURES}

Figure 1

Density of 1970 TSP Levels

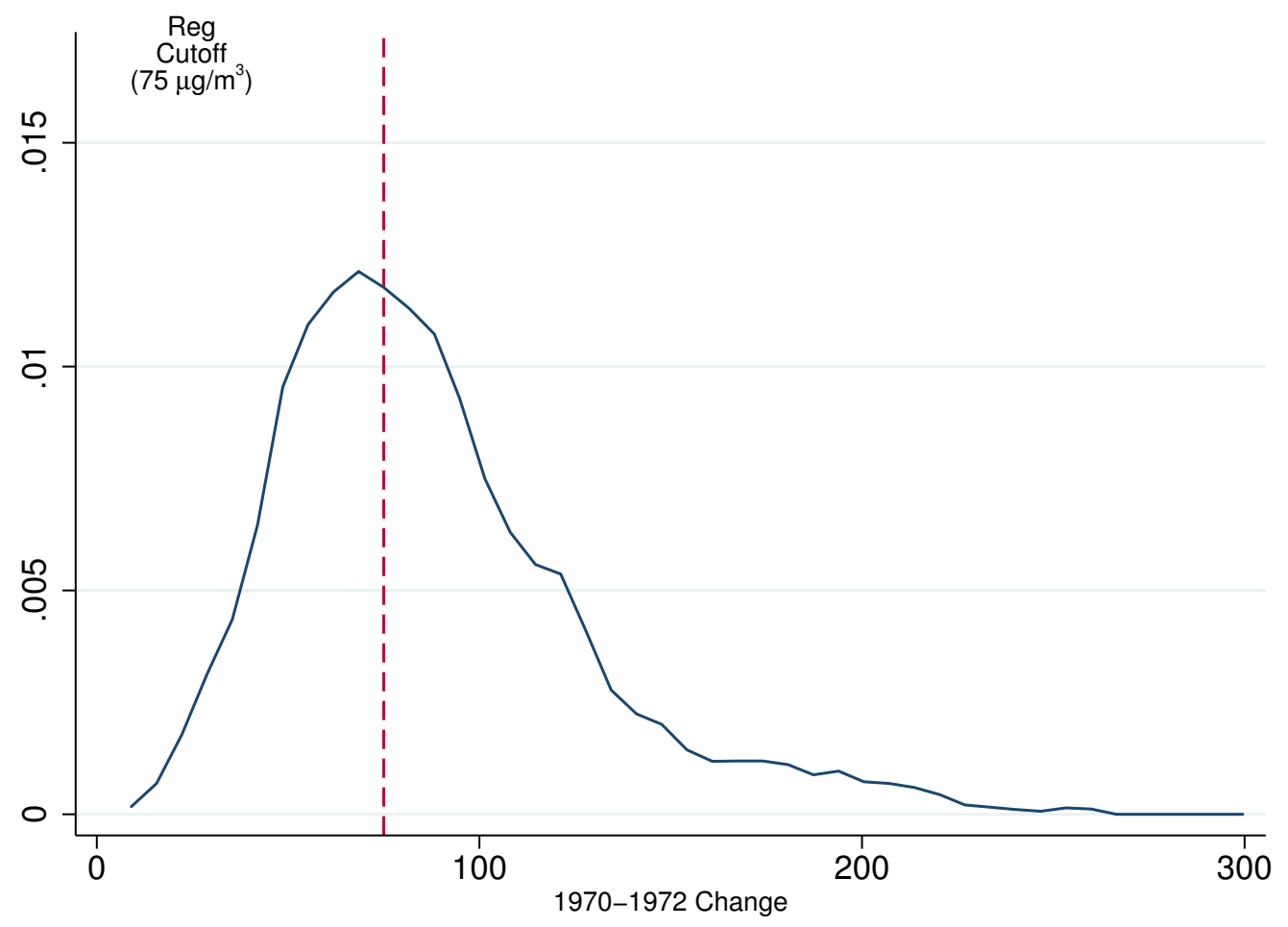

Notes: Kernel density is calculated with a bandwidth of $10 \mu \mathrm{g} / \mathrm{m}^{3}$. County level geometric mean levels are calculated as discussed in Section 5. 
Figure 2

Trends in TSPs by Estimated 1970's Attainment Status

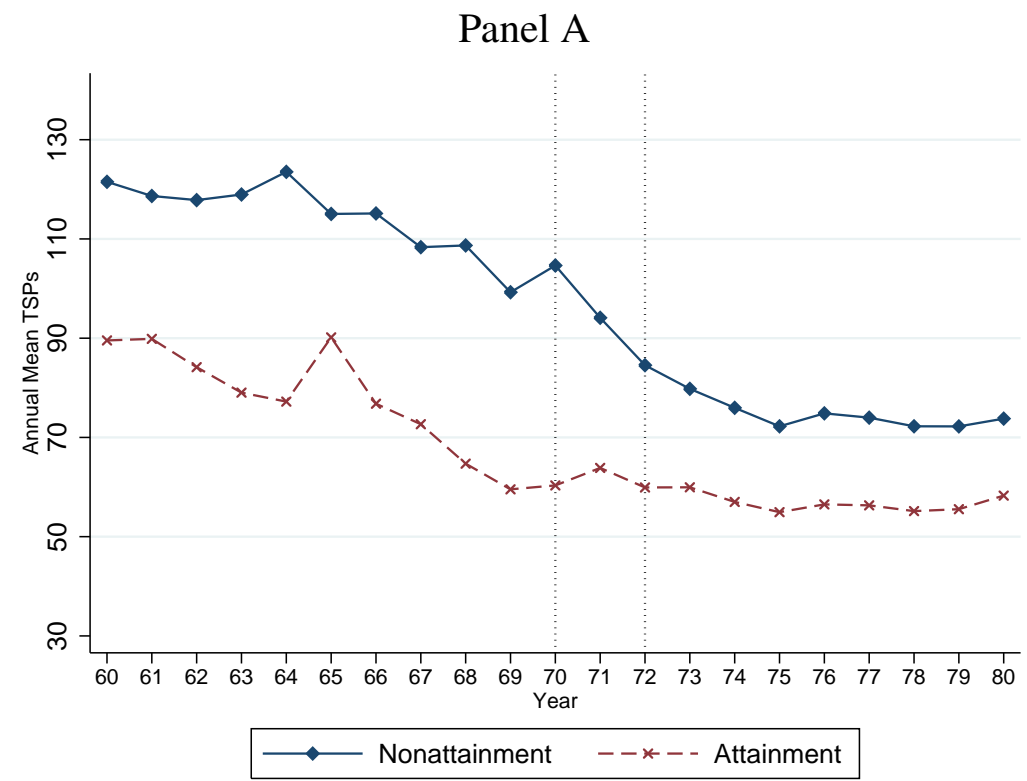

Panel B

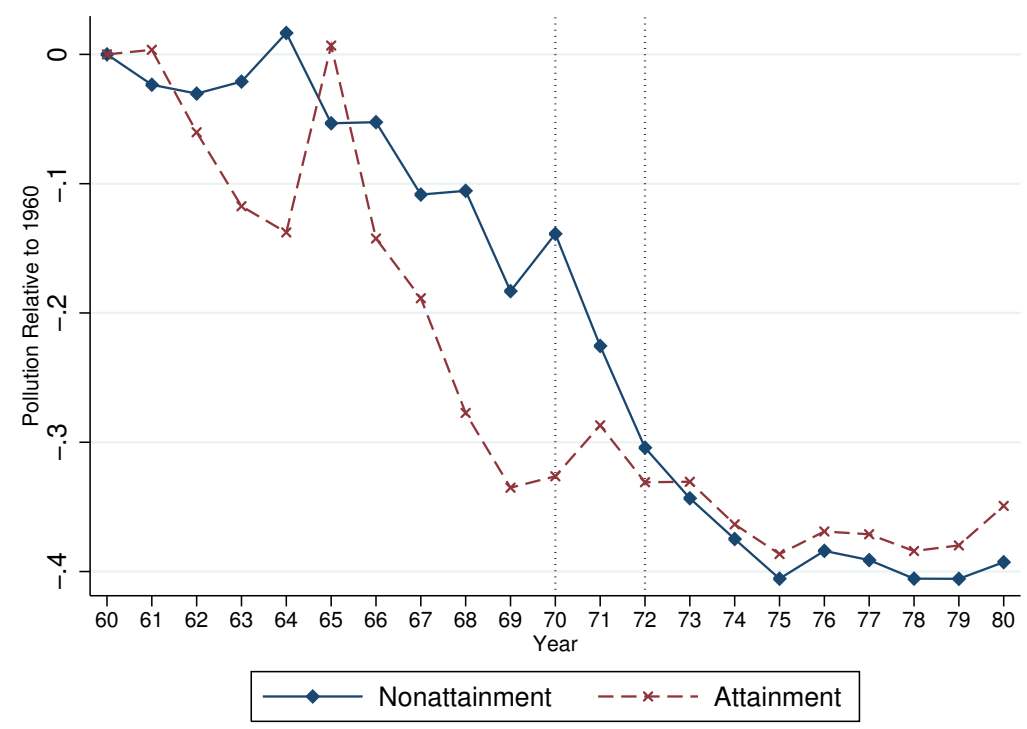

Notes: Yearly values are calculated using pollution data for the 281 counties in the primary analysis. Determination of attainment status is discussed in Section 5. 
Figure 3

Local Linear Estimation of Changes in Arithmetic Mean by 1970 TSP Level

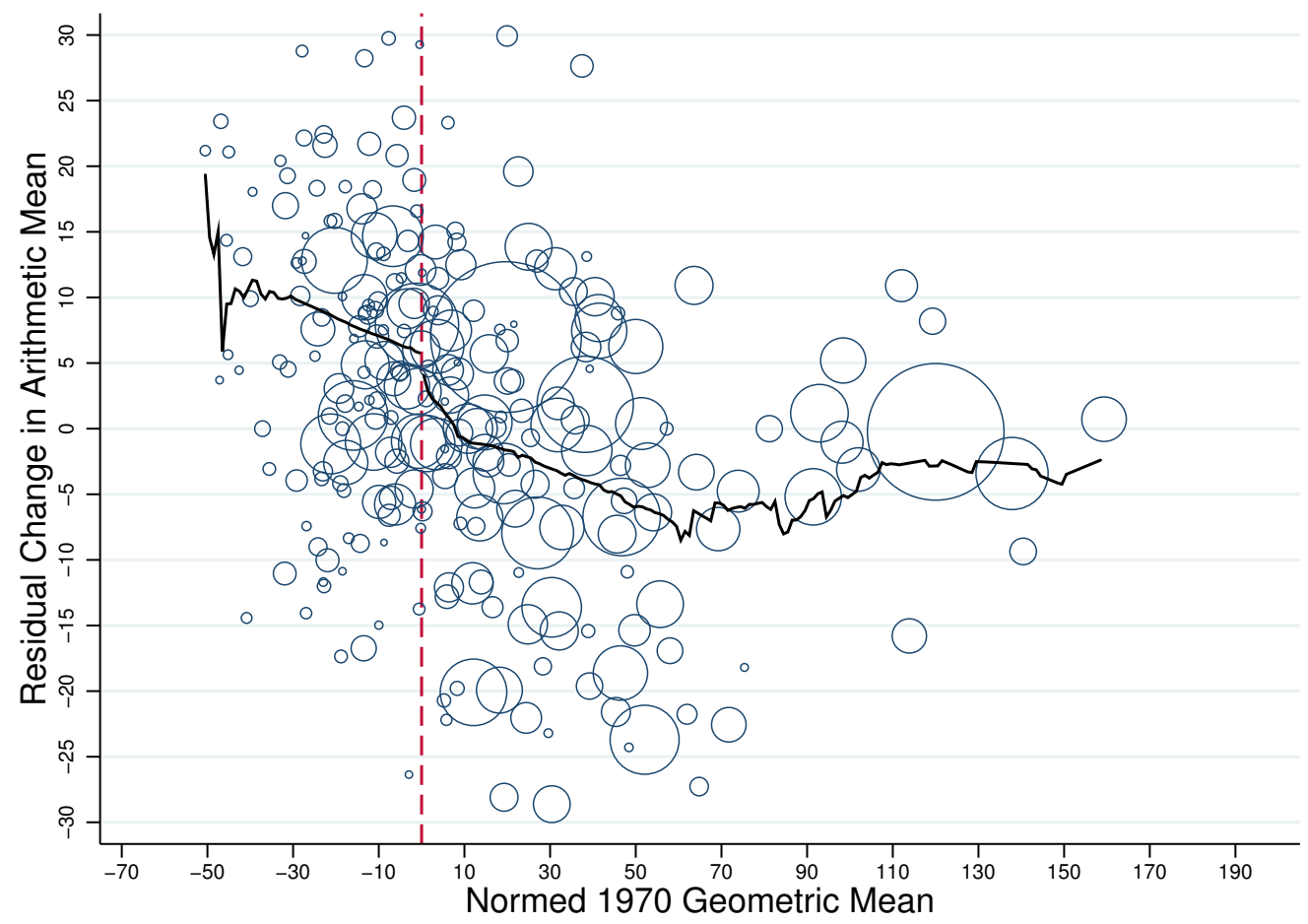

Notes: Local linear estimation is smoothed with a bandwidth of $30 \mu \mathrm{g} / \mathrm{m}^{3}$. County level geometric mean levels are calculated as discussed in Section 5. Counties with arithmetic mean changes greater than $30 \mu \mathrm{g} / \mathrm{m}^{3}$ and less than $-30 \mu \mathrm{g} / \mathrm{m}^{3}$ are omitted from the scatterplot for scale reasons but are included in all local linear regression estimates. 
Figure 4

Changes in Probability of a Live Birth Being Male Between 1970 and 1972

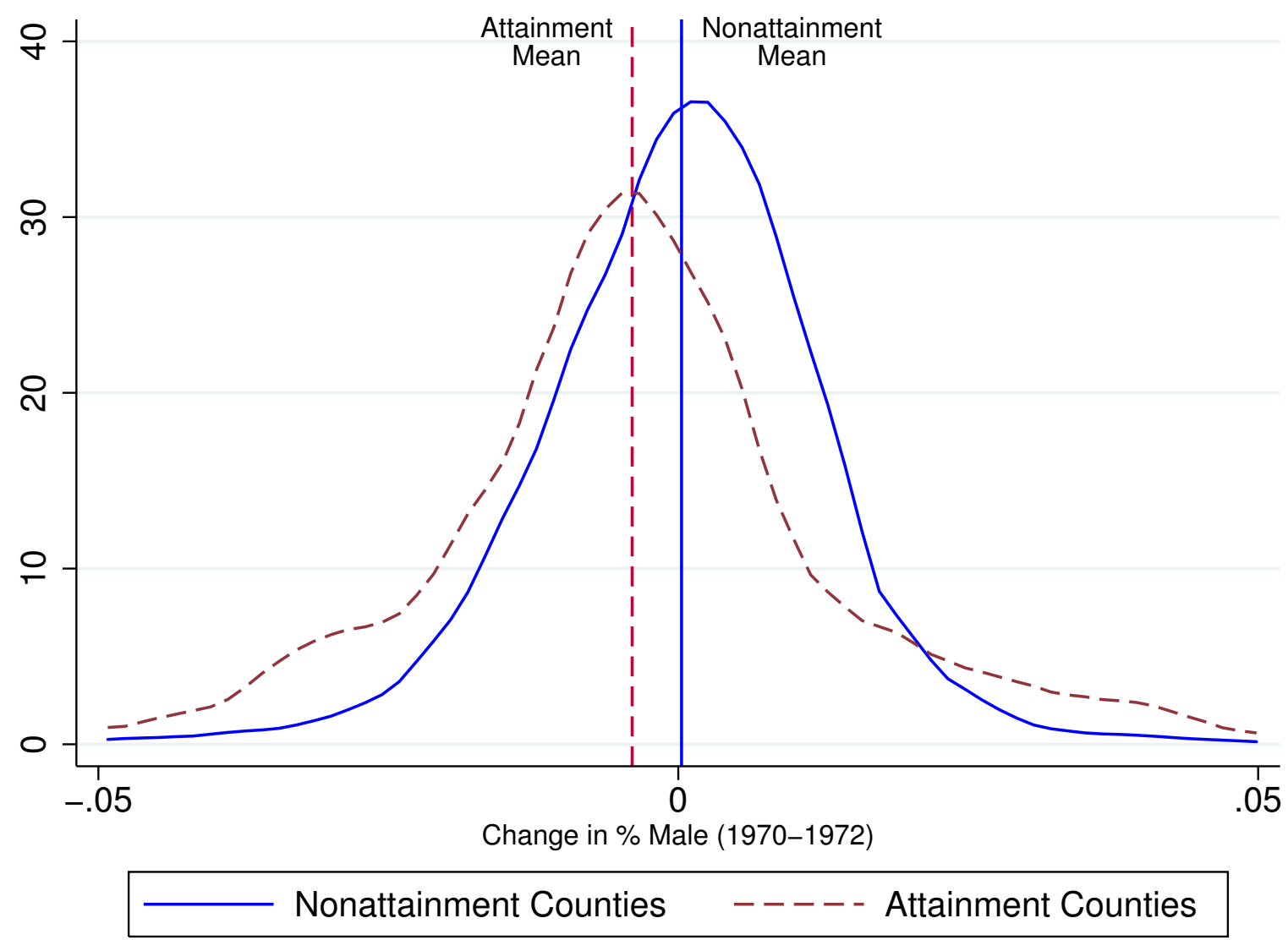

Notes: Kernel density is calculated with a bandwidth of 0.5 percentage points. 
Figure 5

Average TSP Levels by Month 1970-1972

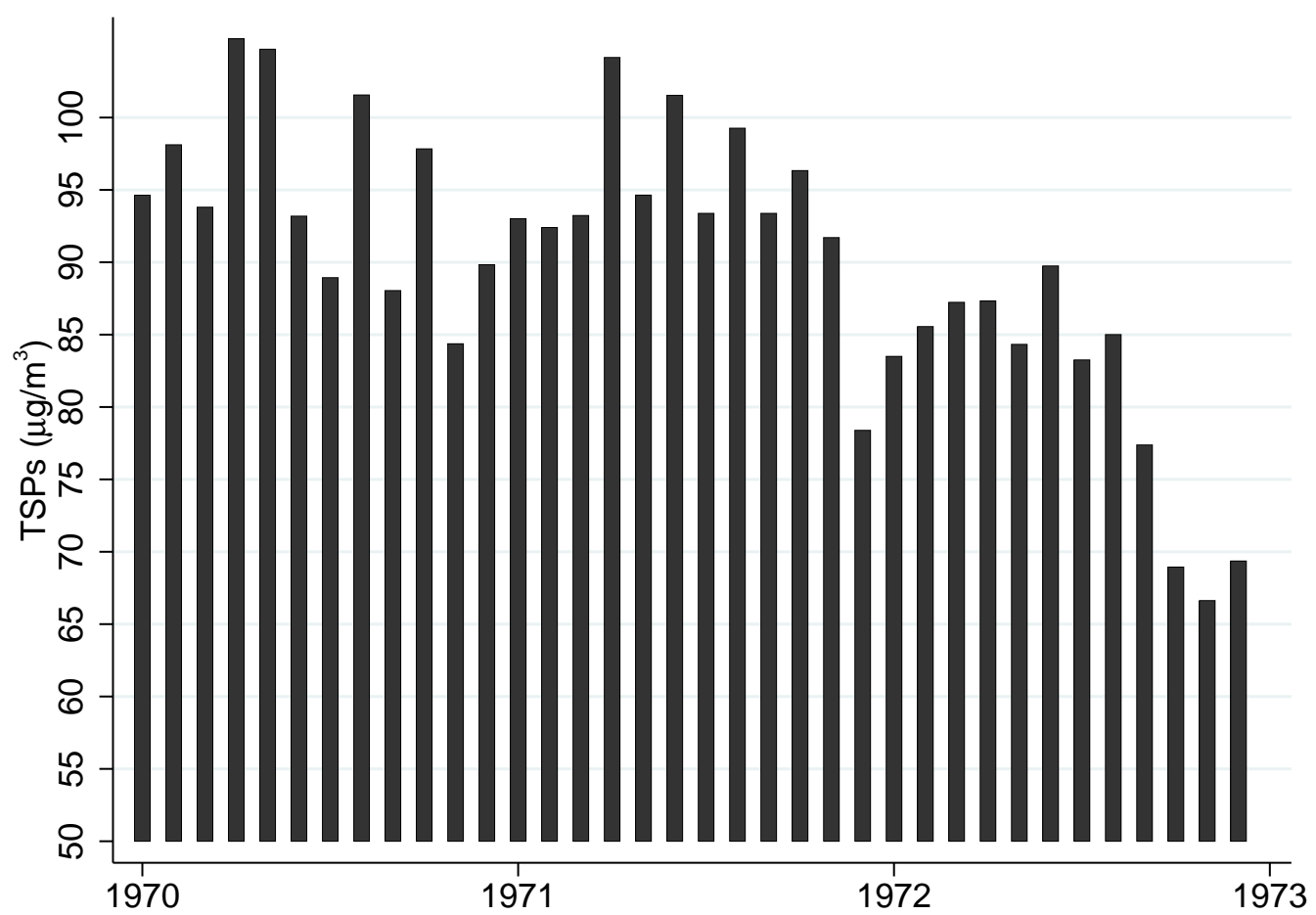

Notes: Values calculated using daily TSP data from all monitors used in the primary analysis and collapsing by month. 


\section{TABLES}

Table 1

Percentage of Live Births that are Male by Subgroup

\begin{tabular}{lcc}
\hline Mother Category & Percentage Male & Births $(1,000)$ \\
\hline Early Prenatal Care & 51.25 & 53,874 \\
Late Prenatal Care & 50.83 & 1,288 \\
Married & 51.31 & 58,571 \\
Single & 51.03 & 11,795 \\
Young & 51.33 & 7,273 \\
Mid & 51.27 & 59,116 \\
Older & 51.11 & 3,978 \\
Black & 50.71 & 11,423 \\
White & 51.38 & 56,659 \\
HS or Less & 51.24 & 35,965 \\
HS and Above & 51.36 & 16,048 \\
QOB1 & 51.23 & 16,962 \\
QOB2 & 51.37 & 17,077 \\
QOB3 & 51.27 & 18,703 \\
QOB4 & 51.20 & 17,625 \\
\hline
\end{tabular}

Notes: Each line presents the mean percentage of live births that are male and total live births by group from 1968-1988. 
Table 2

Differences in Percentage of Live Births that are Male by Subgroup and Year

\begin{tabular}{cccccc}
\hline \multicolumn{5}{c}{ Yearly Differences By Subgroups } \\
\cline { 2 - 6 } Year & $\begin{array}{c}\text { Prenatal } \\
\text { Care }\end{array}$ & $\begin{array}{c}\text { Marital } \\
\text { Status }\end{array}$ & $\begin{array}{c}\text { Mother } \\
\text { Age }\end{array}$ & $\begin{array}{c}\text { Child } \\
\text { Race }\end{array}$ & $\begin{array}{c}\text { Mother } \\
\text { Education }\end{array}$ \\
\hline 1969 & 0.007 & 0.003 & 0.003 & 0.009 & 0.001 \\
1970 & 0.011 & 0.004 & 0.006 & 0.007 & 0.002 \\
1971 & 0.005 & 0.005 & 0.003 & 0.007 & 0.001 \\
1972 & 0.003 & 0.005 & 0.004 & 0.008 & 0.002 \\
1973 & 0.003 & 0.004 & 0.004 & 0.007 & 0.002 \\
1974 & 0.008 & 0.004 & 0.001 & 0.007 & 0.000 \\
1975 & 0.002 & 0.003 & 0.003 & 0.007 & 0.000 \\
1976 & 0.003 & 0.002 & -0.002 & 0.007 & 0.001 \\
1977 & 0.005 & 0.003 & 0.002 & 0.008 & 0.001 \\
1978 & 0.007 & 0.003 & 0.000 & 0.007 & 0.004 \\
1979 & 0.001 & 0.002 & -0.001 & 0.007 & 0.000 \\
1980 & 0.001 & 0.002 & 0.002 & 0.007 & 0.001 \\
1981 & 0.003 & 0.001 & 0.002 & 0.007 & 0.001 \\
1982 & 0.006 & 0.003 & 0.000 & 0.005 & 0.001 \\
1983 & 0.004 & 0.003 & 0.002 & 0.007 & 0.002 \\
1984 & 0.002 & 0.003 & 0.001 & 0.005 & 0.001 \\
1985 & 0.004 & 0.002 & 0.001 & 0.006 & 0.003 \\
1986 & 0.004 & 0.002 & 0.001 & 0.005 & 0.001 \\
1987 & 0.004 & 0.002 & 0.001 & 0.006 & 0.000 \\
1988 & 0.001 & 0.002 & 0.000 & 0.005 & 0.002 \\
\hline & & & & & \\
\hline
\end{tabular}

Notes: Each line presents the difference between live male birth rates by groups described in column headers: first prenatal care (1-3 months - 7-9 months), marital status (married - single), mother age (over 35 - 19-35), child race (white - black) and maternal education (above high school - below high school). 
Table 3

Comparing Change in Covariates from 1970-1972 by Attainment Status

\begin{tabular}{|c|c|c|c|c|c|}
\hline & \multicolumn{4}{|c|}{ Means } & \multirow{3}{*}{$\begin{array}{l}\text { p-value for Difference } \\
\text { in Changes }(95 \%)\end{array}$} \\
\hline & \multicolumn{2}{|c|}{ Attain } & \multicolumn{2}{|c|}{ Nonattain } & \\
\hline & 1970 & 1972 & 1970 & 1972 & \\
\hline \multicolumn{6}{|l|}{ Variables of Interest } \\
\hline Number of Births & 486,178 & 416,028 & $1,255,254$ & $1,041,554$ & - \\
\hline Infant Mortality (one-year) & 1,506 & 1,260 & 1,773 & 1,487 & 0.026 \\
\hline TSPs & 67 & 71 & 102 & 87 & 0.009 \\
\hline$\%$ Low Birth Weight & 0.078 & 0.074 & 0.083 & 0.080 & 0.103 \\
\hline$\%$ Very Low Birth Weight & 0.011 & 0.011 & 0.012 & 0.013 & 0.050 \\
\hline$\%$ Male & 0.514 & 0.511 & 0.512 & 0.513 & 0.053 \\
\hline \multicolumn{6}{|l|}{ Natality Controls } \\
\hline Second Child & 0.285 & 0.306 & 0.275 & 0.296 & 0.676 \\
\hline Third Child or Higher & 0.330 & 0.291 & 0.329 & 0.294 & 0.245 \\
\hline Single Mother & 0.092 & 0.100 & 0.113 & 0.129 & 0.104 \\
\hline White & 0.861 & 0.846 & 0.800 & 0.782 & 0.133 \\
\hline Black & 0.124 & 0.135 & 0.184 & 0.199 & 0.103 \\
\hline Born out of Hospital & 0.003 & 0.005 & 0.002 & 0.004 & 0.975 \\
\hline Physician Present & 0.999 & 0.997 & 0.999 & 0.998 & 0.496 \\
\hline Mother's Age & 24.94 & 24.86 & 24.73 & 24.63 & 0.130 \\
\hline \multicolumn{6}{|l|}{ Economic Controls } \\
\hline Employment Rate & 0.425 & 0.432 & 0.508 & 0.504 & 0.579 \\
\hline Manufacturing Rate & 0.084 & 0.078 & 0.117 & 0.110 & 0.290 \\
\hline Per Capita Income & 23,986 & 25,332 & 25,179 & 26,651 & 0.356 \\
\hline Per Capita Net Earnings & 18,598 & 19,447 & 19,566 & 20,542 & 0.494 \\
\hline Population & 746,880 & 759,729 & $1,896,848$ & $1,875,765$ & 0.145 \\
\hline Per Capita Unemployment Insurance & 127 & 167 & 132 & 161 & 0.155 \\
\hline Per Capita Total Income Transfers & 2,113 & 2,484 & 2,048 & 2,444 & 0.275 \\
\hline Per Capita Public Medical Assistance & 184 & 246 & 188 & 256 & 0.981 \\
\hline Per Capita Medical Transfers & 398 & 482 & 407 & 499 & 0.963 \\
\hline Per Capita Income Maintenance Payments & 289 & 332 & 313 & 408 & 0.008 \\
\hline Per Capita Food Stamp Payments & 26 & 42 & 27 & 49 & 0.109 \\
\hline Per Capita Family Assistance Payments & 159 & 186 & 172 & 237 & 0.004 \\
\hline
\end{tabular}

Notes: Observations are at the county level and weighted by the number of births in the countyyear. TSP measurements are from the EPA Air Quality Database. Natality and mortality data are from the Vital Statistics of the United States. Economic data are from the Regional Economic Information System. Infant deaths are expressed per 100,000 live births. Dollar values are in 2009 terms. Standard errors for tests of differences are clustered at the state level. 
Table 4

The Impact of CAAA Nonattainment Status on Ambient TSPs and the Probability of Live Births Being Male

(1)

(2)

(3)

(4)

Panel A: First Stage — Change in Mean TSPs from 1970-1972
$\begin{array}{rccccc}\text { Classified Nonattainment } & -16.021^{* * * *} & -16.221^{* * *} & -17.578 * * * & -12.064 * * & -11.650 * * * \\ & (4.878) & (5.093) & (4.289) & (4.815) & (3.366)\end{array}$

Panel B: Reduced Form — Impact of Nonattainment on Probability of a Live Birth Being Male
Classified Nonattainment $\quad 0.544 * *$
$0.479 * *$
$0.572 * * *$
$0.960 * * *$
$1.020 * * *$
$(0.216)$
$(0.196)$
$(0.167)$
(0.293)
$(0.357)$

\begin{tabular}{|c|c|c|c|c|c|}
\hline State Effects & $\mathrm{Y}$ & Y & Y & $\mathrm{Y}$ & Y \\
\hline Natality Controls & $\mathrm{N}$ & Y & Y & $\mathrm{Y}$ & $\mathrm{Y}$ \\
\hline REIS Controls & $\mathrm{N}$ & $\mathrm{N}$ & Y & $\mathrm{Y}$ & Y \\
\hline Linear Running Variable & $\mathrm{N}$ & $\mathrm{N}$ & $\mathrm{N}$ & $\mathrm{Y}$ & Y \\
\hline Flexible Slope & $\mathrm{N}$ & $\mathrm{N}$ & $\mathrm{N}$ & $\mathrm{N}$ & $\mathrm{Y}$ \\
\hline Counties & 281 & 281 & 281 & 281 & 281 \\
\hline
\end{tabular}

Data are described in Section 6. Regressions are done at the county-year level and are weighted by the number of live births. Estimated standard errors, clustered by state, are shown in parentheses. Coefficients in Panel B indicate percentage point changes.

$*$ significant at $10 \% ; * *$ significant at $5 \% ; * * *$ significant at $1 \%$ 
Table 5

Probability of a Live Birth Being Male

\begin{tabular}{lcccc}
\hline & $(1)$ & $(2)$ & $(3)$ & $(4)$ \\
\hline & OLS & IV & IV & IV \\
Mean TSPs & 0.004 & $-0.033^{* * *}$ & $-0.080^{* *}$ & $-0.088^{* * *}$ \\
& $(0.006)$ & $(0.011)$ & $(0.034)$ & $(0.027)$ \\
First Stage F & & 16.78 & 6.27 & 11.87 \\
Impact of 1 std dev & 0.1 & -0.77 & -1.89 & -2.09 \\
\hline Linear Running Variable & - & $\mathrm{N}$ & $\mathrm{Y}$ & $\mathrm{Y}$ \\
Flexible Slope & - & $\mathrm{N}$ & $\mathrm{N}$ & $\mathrm{Y}$ \\
\hline Counties & 281 & 281 & 281 & 281 \\
\hline
\end{tabular}

Notes: Data are described in Section 6. Outcome variable is the probability of a live birth being male. Coefficients indicate percentage point changes. Regressions are done at the county-year level and are weighted by number of births. All specifications include state fixed effects and natality and REIS controls detailed in the text. Instrumental variables estimates of the effect of TSP on total births use the first stage estimates shown in Table 4.

$*$ significant at $10 \%$; * significant at $5 \%$; *** significant at $1 \%$ 


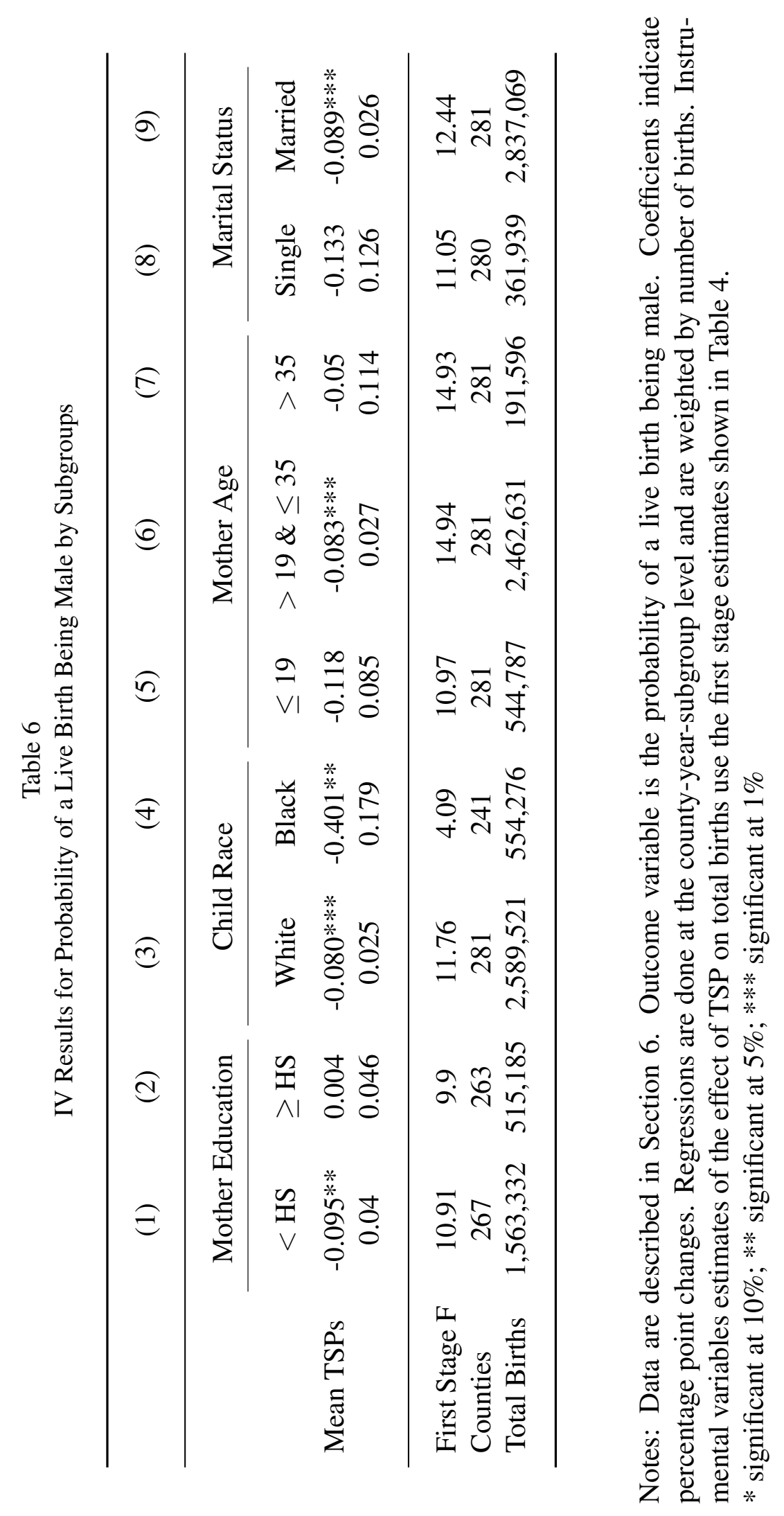


Table 7

Timing of Effects by Quarter of Birth and Trimester

(1)

$(2)$

(3)

(4)

\begin{tabular}{lcccc}
\hline \multicolumn{5}{l}{ Panel A: Effect by Quarter of Birth } \\
Quarter & 1 & 2 & 3 & 4 \\
Mean TSPs & -0.075 & $-0.108^{* *}$ & 0.024 & $-0.138^{* *}$ \\
& $(0.063)$ & $(0.053)$ & $(0.050)$ & $(0.061)$ \\
First Stage Beta & -10.68 & -13.25 & -10.75 & -11.99 \\
First Stage F & 8.96 & 14.42 & 9.82 & 17.23 \\
Counties & 281 & 281 & 280 & 280 \\
\hline
\end{tabular}

Panel B: Effect by Trimester of Exposure

\begin{tabular}{lcccc} 
Trimester & 1 & 2 & 3 & 1,2 ,and 3 (jointly) \\
Mean TSPs & -0.105 & -0.037 & $-0.072 * * *$ & $-0.130 * *$ \\
& $(0.070)$ & $(0.038)$ & $(0.024)$ & $(0.058)$ \\
First Stage Beta & -9.22 & -13.04 & -14.04 & -12.76 \\
First Stage F & 5.14 & 19.88 & 22.13 & 18.72 \\
Counties & 278 & 281 & 281 & 280 \\
\hline
\end{tabular}

Notes: Data are described in Section 6. Outcome variable is the probability of a live birth being male. Coefficients indicate percentage point changes. Regressions are done at the county-year level and are weighted by number of births. See Section 7 for a discussion of how pollution exposure was calculated using daily pollution data. Instrumental variables estimates of the effect of TSP on total births use the first stage estimates shown in Table 4.

$*$ significant at $10 \%$;* significant at $5 \%$; *** significant at $1 \%$ 
Table 8

Estimated Impact on Total Fetal Deaths - Conversion Metrics Using IV Estimates of the Impact of Pollution on Infant Death

\begin{tabular}{cccc}
\hline$(1)$ & $(2)$ & $(3)$ & $(4)$ \\
Male Deaths & Female Deaths & Relative Sensitivity & Impact of CAAA \\
\hline Panel A: Neonatal Mortality Rate & & \\
$17.560^{* *}$ & $12.586^{*}$ & 1.39 & 134,000 \\
$(8.277)$ & $(6.428)$ & & \\
\hline Panel B: One-Year Mortality Rate & & 105,000 \\
$21.999^{*}$ & $14.400^{* *}$ & 1.53 & \\
$(11.243)$ & $(6.378)$ & & \\
\hline
\end{tabular}

Notes: Data are described in Section 6. The regression estimates (Columns 1 and 2 of Panels A and B) show the impact of a one-unit change in TSPs on the probability of a post-natal death. Regressions are done at the county-year level using 281 counties, are weighted by number of births, and control for natality and economic covariates as well as state fixed effects as in column 4 of Table 5. Responses to the CAAA use the estimates from Table 4. Calculations are detailed in Section 8.

$*$ significant at $10 \%$;* significant at $5 \%$; *** significant at $1 \%$ 


\section{A Appendix: Further analysis of the first stage}

We now consider potential confounders to the validity of the regression discontinuity and instrumental variables designs in our analysis such as regression to the mean in pollution and differential background trends between polluting and nonpolluting counties.

\section{A.1 Regression discontinuity: assumptions and potential violations}

We first examine the sensitivity of our results with respect to the identifying assumptions of the discontinuity used in the first stage. The regression discontinuity design is driven by the assumption that counties just over the treatment cutoff serve as good counterfactuals for those just prior to the cutoff. The greater the distance from the cutoff, the higher the probability that treatment and control counties differ in ways for which we have not controlled in our covariate set. One test is to focus the analysis on only those counties that lie close to the cutoff and see if results change, i.e., reducing the "bandwidth" of the analysis. Figure 3 shows that counties just above the cutoff may have behaved differently than those that were more polluted. We explore this further in Figure A-1, which plots local linear estimation of the discontinuity for various data range choices but is otherwise identical to Figure A-1. In each case we assign a regression bandwidth of $30 \mu \mathrm{g} / \mathrm{m}^{3}$ (solid line) for the calculation of any one given point. We also include a simple linear fit with varied slope on either side of the discontinuity as a point of reference (dashed line). In each panel, we vary the amount of data used for estimation, ranging from $20 \mu \mathrm{g} / \mathrm{m}^{3}$ on either side of the cutoff to 120 $\mu \mathrm{g} / \mathrm{m}^{3}$. This allows us to see how the estimates change as we include counties further from the discontinuity. Each of the six restrictions shows a jump in the change of TSPs at the regulatory threshold. However, they jump varies in size, increasing as we include more data, and some of these specifications are not statistically significant as we now show in the numerical results.

We repeat our analysis numerically using a variety of bandwidth choices, ranging from 20 to $60 \mu \mathrm{g} / \mathrm{m}^{3}$. Results are shown in Table A-1, where we display the second stage estimates as well as the first stage estimates and F-statistics. Columns 1-4 show how results vary when we limit the data to counties with 1970 pollution levels within increasingly restricted bandwidths on either side of the regulatory cutoff. There is a tradeoff here between the strength of assumption required for the instrument to be valid and the statistical power available to identify effects. It is more likely that attainment and nonattainment counties are similar on unobservables in this restricted sample than in the full sample we use for our main results.

For bandwidth choices from 60 down to 40, our results remain numerically, though we quickly lose precision. We note that the precision loss is larger than would occur simply due to the smaller number of counties, which suggests that there may be some more extreme polluted counties that increase the precision of our results. In all three cases the estimated impact of attainment status on changes in pollution is approximately the same, which is reassuring for our assumption that changes are not driven simply by mean reversion. Once we move to bandwidths of 30 and below, however, the impact of attainment status decreases dramatically and moves toward zero. This may be in part a result of the imprecision of attainment status assignment, as noted in Section 5. It could be that we lack sufficient power to properly estimate such models. A more concerning possibility is that the first stage is being driven by a more general trend in the difference between polluting and non-polluting counties rather than the CAAA. We examine this possibility below. The attainment 
status of each county for the first binding year of the CAAA was not recorded, and we instead estimate it from existing TSP data. There may be cross contamination of treatment or control groups immediately across the regulatory cutoff. To test if incorrect assignment of attainment status immediately around the threshold is driving the results, we look at results that limit the sample to counties that are not immediately around the discontinuity. Column 6 of Table A-1 presents results that omit the counties that fall within $5 \mu \mathrm{g} / \mathrm{m}^{3}$ of the regulatory cutoff for nonattainment status. While we again lose statistical power, we find a result that is indistinguishable in magnitude and sign from our main specification, indicating this is not an important source of bias.

In Table A-2 we return to the full data set and add smooth higher-order functions of the running variable (geometric mean of pollution in year 1970) and its interaction with attainment status in the first and second stages. This check allows us to see if our identification is arising from a smooth change in pollution across the spectrum, i.e., regression to the mean in higher pollution counties over time, rather than the assumed discontinuity in pollution changes. Column 1 presents a specification that includes a linear control for the initial geometric mean of the TSP level but maintains a constant slope. In column 2, our preferred specification used in the paper body, we add the interaction of that linear control with an indicator for attainment status. Columns 3-6 control for quadratic, cubic, quartic, and quintic forms of the running variable, adding subsequently higher order terms and their interactions. As with the case of restricted bandwidth, the additional strain on the data reduces the predictive strength of the excluded variable, but results remain significant at $10 \%$ using a quadratic. While results are no longer significant when controlling for a cubic functions and higher, the coefficient remains negative and is similar in magnitude to our main effect. Based on the illustrated relationship between the geometric mean and changes in pollution seen in Figure 3, we believe the simple linear relationship is a relatively good approximation of the truth after controlling for covariates and state fixed effects. This is further supported by the included p-values of joint significance for all interacted terms. While the joint strength increases with the allowance of varied linear slope on either side, adding higher order terms gains nothing. Table A-3 repeats this analysis for the first stage only, and we find similar results - higher order interactions beyond linear provide no additional explanatory information.

\section{A.2 IV validity: trends in pollution and gender ratios}

Nonattainment status may have been assigned to counties that already had either a negative pollution trend or a positive trend in the percent of each birth cohort that were male. Ideally we would examine county-level trends prior to the CAAA by attainment status. As noted in Section 6, detailed natality data do not exist prior to 1968 and the earlier TSP data are similarly unavailable or unreliable. In the absence of such data from the pre-period we examine trends in the post-period. We repeat the analysis first looking at the impact of 1970 attainment status on subsequent two-year drops in pollution. If a difference in trends between attainment and nonattainment counties is responsible for our first stage findings rather than an exogenous policy shock, this trend would likely

continue in the years after our analysis. Panel A of Table A-4 presents these results. Column 1 presents our first stage that looks at the impact of 1970 attainment status on the pollution decline between 1970-1972. Columns 2-6 present falsification tests looking at other pollution declines. The number of counties changes slightly across specifications due to availability of REIS data across periods. Point estimates are generally not significant, and for no other period is the estimated effect 
as large as our period of interest. This is suggestive evidence that any background trends in pollution declines do not continue after the implementation of the CAAA. However, there are other periods that have statistically significant results. Column 4 shows large, positive effects, though they are only marginally significant. Column 6 has smaller positive effects, though results are now statistically significant at conventional levels. This may indicate that counties in nonattainment in 1970 saw different economic development trends in later years. However, there is no constant statistical difference over time, which suggests there may not be background trends in pollution by attainment status. Additionally, such countervailing increases in pollution in nonattainment counties would be more concerning were they immediately after the decreases in pollution we assign to the CAAA. While they are still concerning, since they occur 15 years later, they are less likely to indicate the measured impact of the CAAA was purely an accounting trick.

We next examine trends after the period of interest in gender ratios. Again lacking pre-data, we instead look for persistent trends after the implementation of the CAAA. Here we use the 1970-1972 pollution changes, but assign them to the controls and gender ratios of other two-year difference pairs, ranging from 1973-1975 up through 1985-1987. If background trends in gender ratios are driving our results and those trends persist after implementation of the CAAA we should observe them as persistent, statistically significant, negative impacts of increased pollution on the percent male. Results are shown in Table A-4. Column 1 repeats our main estimates (19701972), and columns 2-6 show the results using natality and economic covariate data from later two-year periods. Results are not significant at conventional for any other two-year pair, and more importantly we can rule out point estimates for any of these relationships as large as the main effect.

Finally, we tested to see if the choice of the two-year 1970-1972 difference is of importance. As noted in Section 4, we prefer to use this two-year window to allow for a "before" and "after" of the enactment of the CAAA. However, since there are other possible choices for a "pre" period, we have repeated our analysis using a three-year window spanning the CAAA (1969-1972) and a one-year window (1971-1972). Prior to controlling for the running variable, the results are robust to choice of data window. After adding the running variable, all results remain negative, though the values are substantially noisier. Due to large standard errors, we cannot reject equality of the estimates across year specifications (an F-test of coefficient equality yielded a p-value of 0.73 ). These results are available upon request. 
Figure A-1

Local Linear Estimation of Changes in Arithmetic Mean by 1970 TSP Level: Varied Data Range
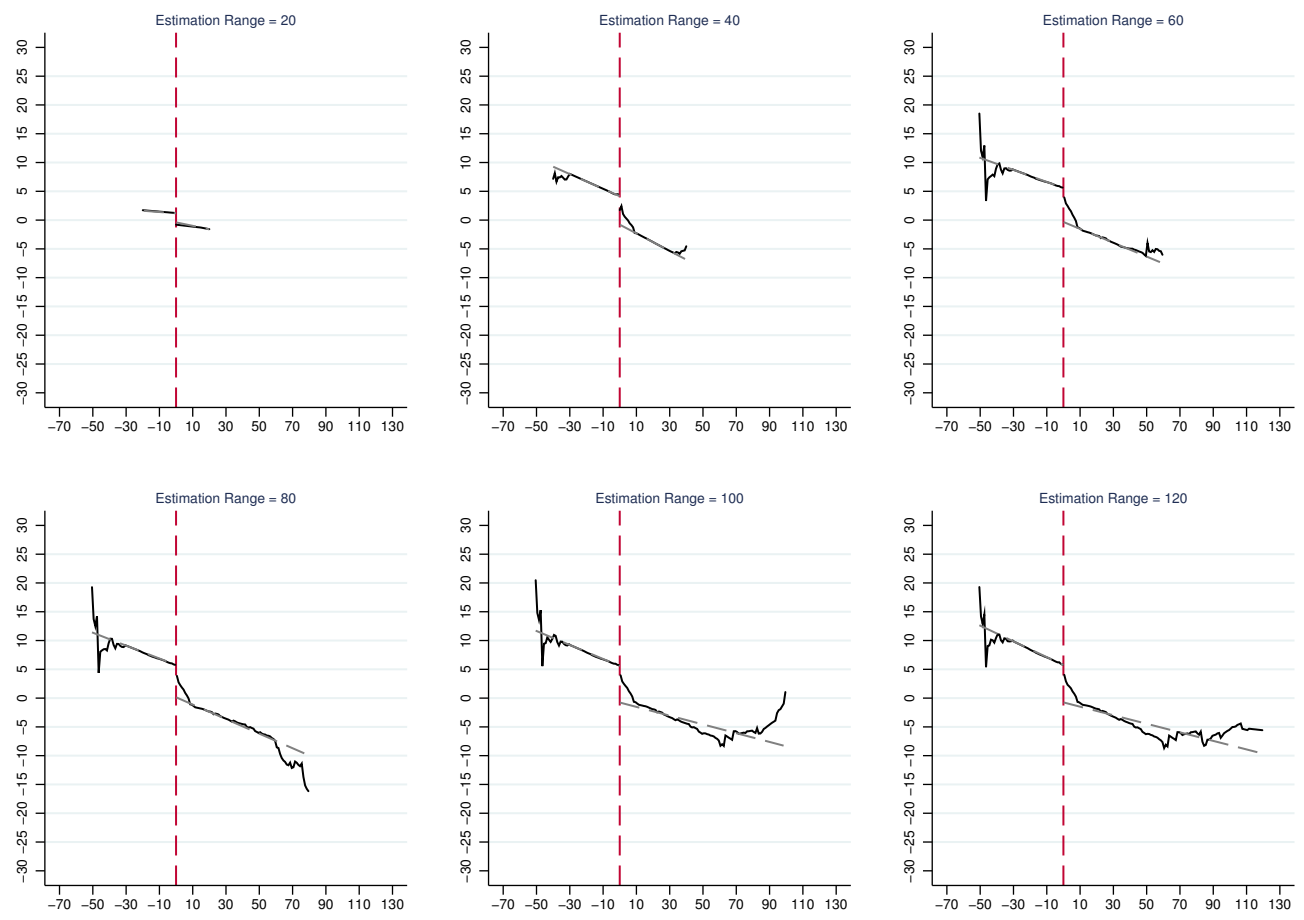

Notes: Local linear estimation of the change in 1970-1972 TSP graphed against 1970 TSP relative to the regulatory threshold is estimated with a bandwidth of $30 \mu \mathrm{g} / \mathrm{m}^{3}$. Each graph includes counties in successively wider data ranges around the regulatory threshold. The right hand side variable is the residual of the change in TSP after controlling for all control variables included in the main specification. 
Table A-1

IV Estimates Using Varied Bandwidths

\begin{tabular}{lccccc}
\hline & $(1)$ & $(2)$ & $(3)$ & $(4)$ & $(5)$ \\
\hline 1970 TSP Range & $+/-60 \mu \mathrm{g} / \mathrm{m}^{3}$ & $+/-40 \mu \mathrm{g} / \mathrm{m}^{3}$ & $+/-30 \mu \mathrm{g} / \mathrm{m}^{3}$ & $+/-20 \mu \mathrm{g} / \mathrm{m}^{3}$ & $>+/<-20 \mu \mathrm{g} / \mathrm{m}^{3}$ \\
Mean TSPs & $-0.093 *$ & -0.076 & -0.111 & -0.317 & -0.073 \\
& $(0.05)$ & $(0.06)$ & $(0.139)$ & $(0.422)$ & $(0.059)$ \\
Counties & 254 & 217 & 185 & 136 & 250 \\
Births & $2,648,932$ & $2,209,526$ & $1,859,609$ & $1,508,446$ & $2,832,824$ \\
First Stage Beta & -10.27 & -10.15 & -5.1 & -3.28 & -11.61 \\
First Stage F & 3.03 & 5.34 & 1.25 & 1.07 & 2.31 \\
\end{tabular}

Notes: Data are described in Section 6. Outcome variable is the probability of a live birth being male. Coefficients indicate percentage point changes. Regressions are done at the county-year level and are weighted by number of births. Instrumental variables estimates of the effect of TSP on total births use the first stage estimates shown in Table 4. Columns 1 through 4 limit analysis to counties close to the $75 \mu \mathrm{g} / \mathrm{m}^{3}$ regulatory threshold. Column 5 uses all counties except those immediately around the regulatory threshold.

* significant at $10 \%$; ** significant at $5 \%$; *** significant at $1 \%$ 
Table A-2

IV Estimates with Varied-Order Polynomials

\begin{tabular}{lccccc}
\hline & $(1)$ & $(2)$ & $(3)$ & $(4)$ & $(5)$ \\
& Linear & Quadratic & Cubic & Quartic & Quintic \\
Mean TSPs & $-0.088^{* * *}$ & $-0.123^{*}$ & -0.266 & -0.321 & -0.189 \\
& $(0.027)$ & $(0.069)$ & $(0.299)$ & $(0.434)$ & $(0.227)$ \\
Counties & 281 & 281 & 281 & 281 & 281 \\
Births & $3,199,014$ & $3,199,014$ & $3,199,014$ & $3,199,014$ & $3,199,014$ \\
First Stage Beta & -11.65 & -8.39 & -6.33 & -4.7 & -5.22 \\
First Stage F & 11.87 & 3.37 & 0.55 & 0.00 & 0.00 \\
p-value of Add. Running Var. & 0.0133 & 0.1619 & 0.763 & 0.9043 & 0.854 \\
\hline
\end{tabular}

Notes: Data are described in Section 6. Outcome variable is the probability of a live birth being male. Coefficients indicate percentage point changes. Regressions are done at the county-year level and are weighted by number of births. See Section 7 for a discussion of how pollution exposure was calculated using daily pollution data. Instrumental variables estimates of the effect of TSP on total births use the first stage estimates shown in Table 4. Each specification includes successively higher powers of 1970 TSP level and an interaction of each of these variables with an indicator for attainment status. Listed p-value is the joint significance of all TSP terms.

* significant at $10 \%$; * significant at 5\%; *** significant at $1 \%$ 
Table A-3

First Stage Estimates with Varied-Order Polynomials

\begin{tabular}{|c|c|c|c|c|c|c|}
\hline & (1) & (2) & (3) & (4) & (5) & (6) \\
\hline Classified Nonattainment & $\begin{array}{c}-12.064 * * \\
(4.815)\end{array}$ & $\begin{array}{c}-11.650^{* * *} \\
(3.366)\end{array}$ & $\begin{array}{l}-8.387^{*} \\
(4.573)\end{array}$ & $\begin{array}{l}-6.329 \\
(7.973)\end{array}$ & $\begin{array}{l}-4.701 \\
(7.286)\end{array}$ & $\begin{array}{l}-5.218 \\
(7.173)\end{array}$ \\
\hline Constant Linear & $\begin{array}{c}-0.118 * * * \\
(0.040)\end{array}$ & & & & & \\
\hline$<75$ & & $\begin{array}{l}-0.153 \\
(0.217)\end{array}$ & $\begin{array}{l}-0.088 \\
(0.853)\end{array}$ & $\begin{array}{l}-0.597 \\
(1.612)\end{array}$ & $\begin{array}{l}-0.163 \\
(1.613)\end{array}$ & $\begin{array}{c}0.11 \\
(3.175)\end{array}$ \\
\hline$>75$ & & $\begin{array}{c}-0.117^{* *} \\
(0.045)\end{array}$ & $\begin{array}{c}-0.287 * * \\
(0.121)\end{array}$ & $\begin{array}{c}-0.35 \\
(0.311)\end{array}$ & $\begin{array}{c}-0.672^{*} \\
(0.393)\end{array}$ & $\begin{array}{l}-0.615 \\
(0.613)\end{array}$ \\
\hline$<75$ squared & & & $\begin{array}{c}0.002 \\
(0.019)\end{array}$ & $\begin{array}{l}-0.031 \\
(0.075)\end{array}$ & $\begin{array}{c}0.021 \\
(0.153)\end{array}$ & $\begin{array}{c}0.068 \\
(0.601)\end{array}$ \\
\hline$>75$ squared & & & $\begin{array}{c}0.001 \\
(0.001)\end{array}$ & $\begin{array}{c}0.002 \\
(0.006)\end{array}$ & $\begin{array}{c}0.013 \\
(0.012)\end{array}$ & $\begin{array}{c}0.01 \\
(0.028)\end{array}$ \\
\hline$<75$ cubed & & & & $\begin{array}{l}-0.001 \\
(0.001)\end{array}$ & $\begin{array}{c}0.001 \\
(0.006)\end{array}$ & $\begin{array}{c}0.004 \\
(0.037)\end{array}$ \\
\hline$>75$ cubed & & & & $\begin{array}{c}0.000 \\
(0.000)\end{array}$ & $\begin{array}{c}0.000 \\
(0.000)\end{array}$ & $\begin{array}{c}0.000 \\
(0.000)\end{array}$ \\
\hline$<75$ quartic & & & & & $\begin{array}{c}0.000 \\
(0.000)\end{array}$ & $\begin{array}{c}0.000 \\
(0.001)\end{array}$ \\
\hline$>75$ quartic & & & & & $\begin{array}{c}0.000 \\
(0.000)\end{array}$ & $\begin{array}{c}0.000 \\
(0.000)\end{array}$ \\
\hline$<75$ quintic & & & & & & $\begin{array}{c}0.000 \\
(0.000)\end{array}$ \\
\hline$>75$ quintic & & & & & & $\begin{array}{c}0.000 \\
(0.000)\end{array}$ \\
\hline p-value of Add. Running Var. & 0.0056 & 0.0025 & 0.0092 & 0.0254 & 0.0369 & 0.1352 \\
\hline
\end{tabular}

Notes: Data are described in Section 6. Outcome variable is the probability of a live birth being male. Coefficients indicate percentage point changes. Regressions are done at the county-year level and are weighted by number of births. See Section 7 for a discussion of how pollution exposure was calculated using daily pollution data. Instrumental variables estimates of the effect of TSP on total births use the first stage estimates shown in Table 4. Each specification includes successively higher powers of 1970 TSP level and an interaction of each of these variables with an indicator for attainment status. Listed p-value is the joint significance of all TSP terms.

* significant at $10 \% ; * *$ significant at $5 \% ; * * *$ significant at $1 \%$ 
Table A-4

Repeated IV Results Assigning 70-72 Pollution to Various Year-Pairs

\begin{tabular}{|c|c|c|c|c|c|c|}
\hline & (1) & (2) & (3) & (4) & $(5)$ & (6) \\
\hline & $70-72$ & $73-75$ & 76-78 & $79-81$ & $82-84$ & $85-87$ \\
\hline \multicolumn{7}{|c|}{ Panel A: Impact of the 1970 CAAA on other period pollution changes } \\
\hline Mean TSPs & $\begin{array}{c}-11.650 * * * \\
(3.366)\end{array}$ & $\begin{array}{l}-0.507 \\
(4.550)\end{array}$ & $\begin{array}{l}-2.166 \\
(2.045)\end{array}$ & $\begin{array}{l}7.606 * \\
(4.467)\end{array}$ & $\begin{array}{c}1.299 \\
(1.828)\end{array}$ & $\begin{array}{c}4.373 * * \\
(1.902)\end{array}$ \\
\hline Counties & 281 & 261 & 254 & 247 & 245 & 218 \\
\hline \multicolumn{7}{|c|}{ Panel B: Changes in other period gender ratios using 1970-1972 pollution change } \\
\hline Mean TSPs & $\begin{array}{c}-0.088 * * * \\
(0.027)\end{array}$ & $\begin{array}{c}0.013 \\
(0.030)\end{array}$ & $\begin{array}{l}-0.042 \\
(0.030)\end{array}$ & $\begin{array}{c}0.034 \\
(0.029)\end{array}$ & $\begin{array}{c}-0.023 * \\
(0.014)\end{array}$ & $\begin{array}{c}0.014 \\
(0.017)\end{array}$ \\
\hline First Stage F & 11.87 & 7.12 & 12.61 & 4.54 & 5.96 & 8.18 \\
\hline Counties & 281 & 278 & 280 & 281 & 281 & 281 \\
\hline
\end{tabular}

Notes: Data are described in Section 6. Outcome variable is the probability of a live birth being male. Coefficients indicate percentage point changes. Regressions are done at the county-year level and are weighted by number of births. Column 1 repeats the result from column 4 of Table 5, all other columns use 1970-1972 pollution changes but all other data from indicated two-year difference span (see Section A). Instrumental variables estimates of the effect of TSP on total births use the first stage estimates shown in Table 4.

* significant at $10 \%$; ** significant at 5\%; *** significant at $1 \%$ 


\section{B Appendix: Additional tables}

Table B-1

OLS and IV of Gender Ratios: Varied Covariate Sets

\begin{tabular}{|c|c|c|c|c|}
\hline & (1) & (2) & (3) & (4) \\
\hline \multicolumn{5}{|l|}{ Panel A: OLS } \\
\hline Mean TSP & $\begin{array}{c}0.000 \\
(0.003)\end{array}$ & $\begin{array}{c}0.005 \\
(0.006)\end{array}$ & $\begin{array}{c}0.006 \\
(0.005)\end{array}$ & $\begin{array}{c}0.004 \\
(0.006)\end{array}$ \\
\hline \multicolumn{5}{|l|}{ Panel B: IV } \\
\hline Mean TSP & $\begin{array}{c}-0.098 \\
(0.118)\end{array}$ & $\begin{array}{c}-0.110^{*} \\
(0.062)\end{array}$ & $\begin{array}{c}-0.106 * * \\
(0.054)\end{array}$ & $\begin{array}{c}-0.088 * * * \\
(0.027)\end{array}$ \\
\hline State Effects & $\mathrm{N}$ & Y & Y & $\mathrm{Y}$ \\
\hline Natality Controls & $\mathrm{N}$ & $\mathrm{N}$ & $\mathrm{Y}$ & $\mathrm{Y}$ \\
\hline REIS Controls & $\mathrm{N}$ & $\mathrm{N}$ & $\mathrm{N}$ & $\mathrm{Y}$ \\
\hline
\end{tabular}

Notes: Data are described in Section 6. Outcome variable is the probability of a live birth being male. Coefficients indicate percentage point changes. Regressions are done at the county-year level and are weighted by number of births.

* significant at $10 \%$; * significant at $5 \%$; *** significant at $1 \%$ 